\title{
Nutrigenomics as a tool to study the impact of diet on aging and age-related diseases: the Drosophila approach
}

\author{
Zoi Evangelakou ${ }^{\dagger}$, Maria Manola ${ }^{\dagger}$, Sentiljana Gumeni and loannis P. Trougakos ${ }^{*}$
}

\begin{abstract}
Aging is a complex phenomenon caused by the time-dependent loss of cellular homeodynamics and consequently of physiological organismal functions. This process is affected by both genetic and environmental (e.g., diet) factors, as well as by their constant interaction. Consistently, deregulation of nutrient sensing and signaling pathways is considered a hallmark of aging. Nutrigenomics is an emerging scientific discipline that studies changes induced by diet on the genome and thus it considers the intersection of three topics, namely health, diet, and genomics. Model organisms, such as the fruit fly Drosophila melanogaster, have been successfully used for in vivo modeling of higher metazoans aging and for nutrigenomic studies. Drosophila is a well-studied organism with sophisticated genetics and a fully annotated sequenced genome, in which $\sim 75 \%$ of human disease-related genes have functional orthologs. Also, flies have organs/tissues that perform the equivalent functions of most mammalian organs, while discrete clusters of cells maintain insect carbohydrate homeostasis in a way similar to pancreatic cells. Herein, we discuss the mechanistic connections between nutrition and aging in Drosophila, and how this model organism can be used to study the effect of different diets (including natural products and/or their derivatives) on higher metazoans longevity.
\end{abstract}

Keywords: Aging, Diet, Drosophila, Foxo, Insulin signaling, Nrf2, Nutrigenomics, Nutrition, Tor

\section{Introduction}

Drosophila melanogaster has been used for long as a vanguard model organism for genetic studies and for the analysis of molecular mechanisms underlying development, behavior, and diseases. Also, its unique features make Drosophila an effective experimental model for aging research as it has a relatively small body size; a very rapid life cycle $(\sim 10-14$ days depending on the environmental temperature) and a quite short lifespan, which is inversely proportional to increased temperature and fecundity [1]. Furthermore, Drosophila has four different developmental stages, namely, the embryo, larva, pupa, and adult. Since each developmental stage has its own specific experimental advantages, the fly may be considered as a model of multiple organisms that can be dissected and genetically manipulated [2]. Moreover,

\footnotetext{
* Correspondence: itrougakos@biol.uoa.gr

Zoi Evangelakou and Maria Manola equal contribution.

Department of Cell Biology and Biophysics, Faculty of Biology, National and Kapodistrian University of Athens, 15784 Athens, Greece
}

Drosophila is comparatively easier and cheaper (as compared, for instance, to mice) to maintain in large numbers and has a relatively low cost of rearing and housing. Given the genetic tractability and the many tools available for forward and reverse genetics (e.g., the GAL4/ UAS system, RNAi, CRISPR/Cas9, transposon-mediated mutagenesis or excision, chemically induced mutations, etc.), studies can be performed more rapidly, including those that refer to the development of human disease models [3-6].

The fly genome is completely sequenced and encodes 14,000 genes, of which more than $60 \%$ share homology with human genes. Moreover, approximately $75 \%$ of disease-related genes in humans have a functional homo$\log$ in the fly and many of the physiological pathways, such as superoxide metabolism, insulin-like signaling, DNA damage and antioxidant responses, proteostatic, and mitostatic networks, are highly conserved between Drosophila melanogaster and vertebrates [7-10]. Drosophila have organs/tissues that are equivalent to mammalian nervous

(c) The Author(s). 2019 Open Access This article is distributed under the terms of the Creative Commons Attribution 4.0 International License (http://creativecommons.org/licenses/by/4.0/), which permits unrestricted use, distribution, and 
system, heart, digestive system, kidney, adipose tissue, and reproductive tract [11-13] (Fig. 1); also, flies display complex behaviors and responses such as active and rest periods, mating, responses to alterations in temperature and food composition, and also a complex circadian cycle $[14,15]$.
Aging is a complex stochastic process of progressive accumulation of biomolecular damage that varies between individuals due to the interplay of genetic and environmental factors. Consequently, aging is invariably characterized by several distinct signs known as hallmarks of aging (Fig. 2). These include genomic
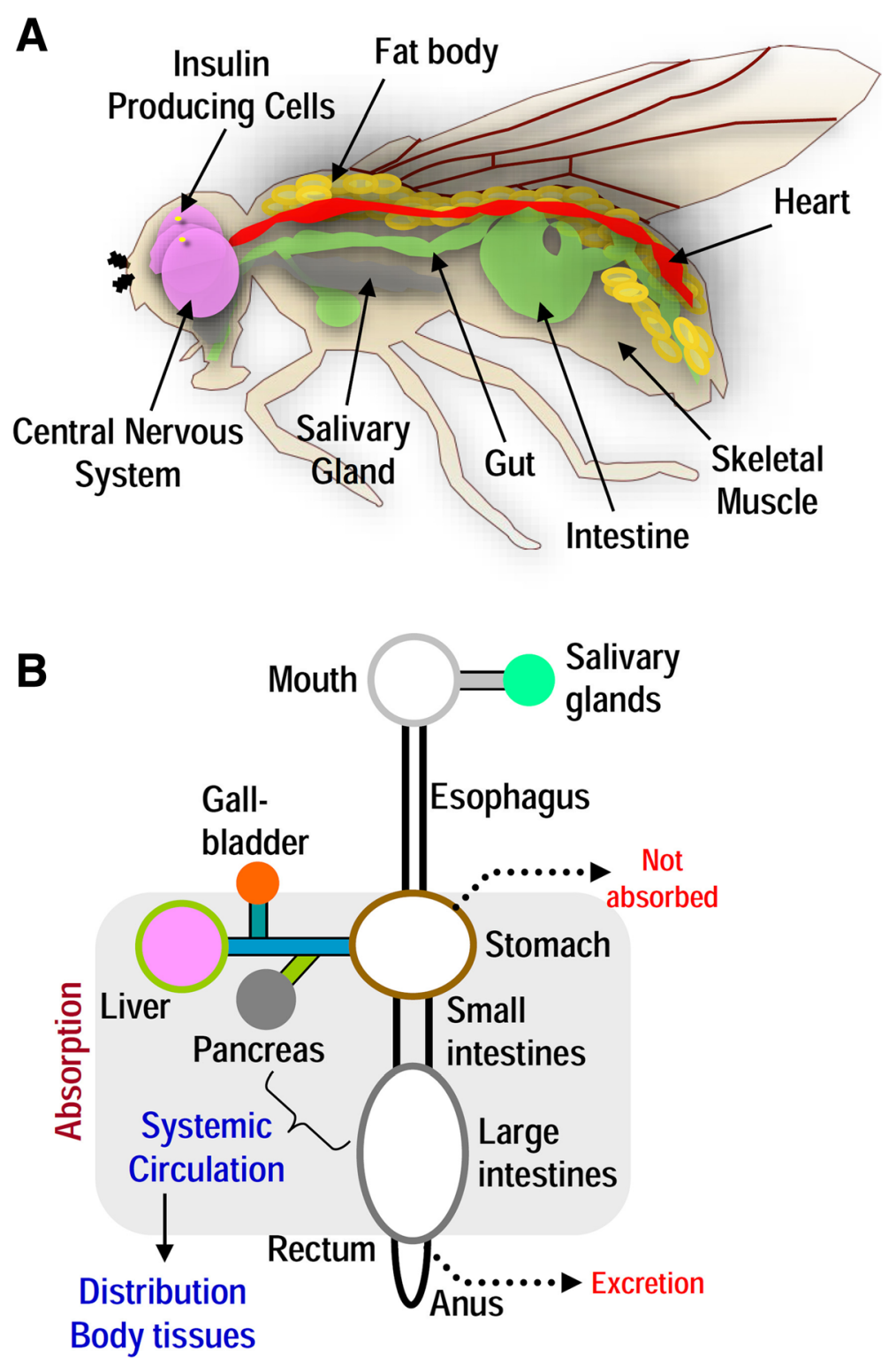

Fig. 1 Drosophila melanogaster as a model organism for nutrigenomics and its translational impact. a The fruit fly has emerged as an excellent model organism to study nutrigenomics in aging and age-related diseases. Drosophila is well-suited in this line of research due to the highly annotated and significantly conserved (compared to mammals) genome. Notably, 75\% of disease-related genes in humans have functional orthologs in the fly, while there are significant similarities in organs that perform the equivalent functions of the mammalian heart, lung, kidney, gut, liver, adipose tissue, and reproductive tract. Drosophila is characterized by well-developed and complex neural and circulatory systems; the latter is composed of a pumping heart tube that through hemolymph circulates regulatory molecules (e.g., insulin-like peptides) to peripheral tissues. Discrete clusters of cells in the brain, muscle, and fat body maintain insect carbohydrate homeostasis in a way similar to pancreatic a- and $\beta$-cells. Drosophila exerts several complex physiological functions, such as nutrients digestion, absorption, and post-absorption processes making this organism an ideal in vivo experimental platform for nutrigenomics studies. $\mathbf{b}$ As most of the components of the human digestive system (shown here diagrammatically) have equivalent modules in the fly model, the latter can be used in nutritional sciences and nutrigenomics 


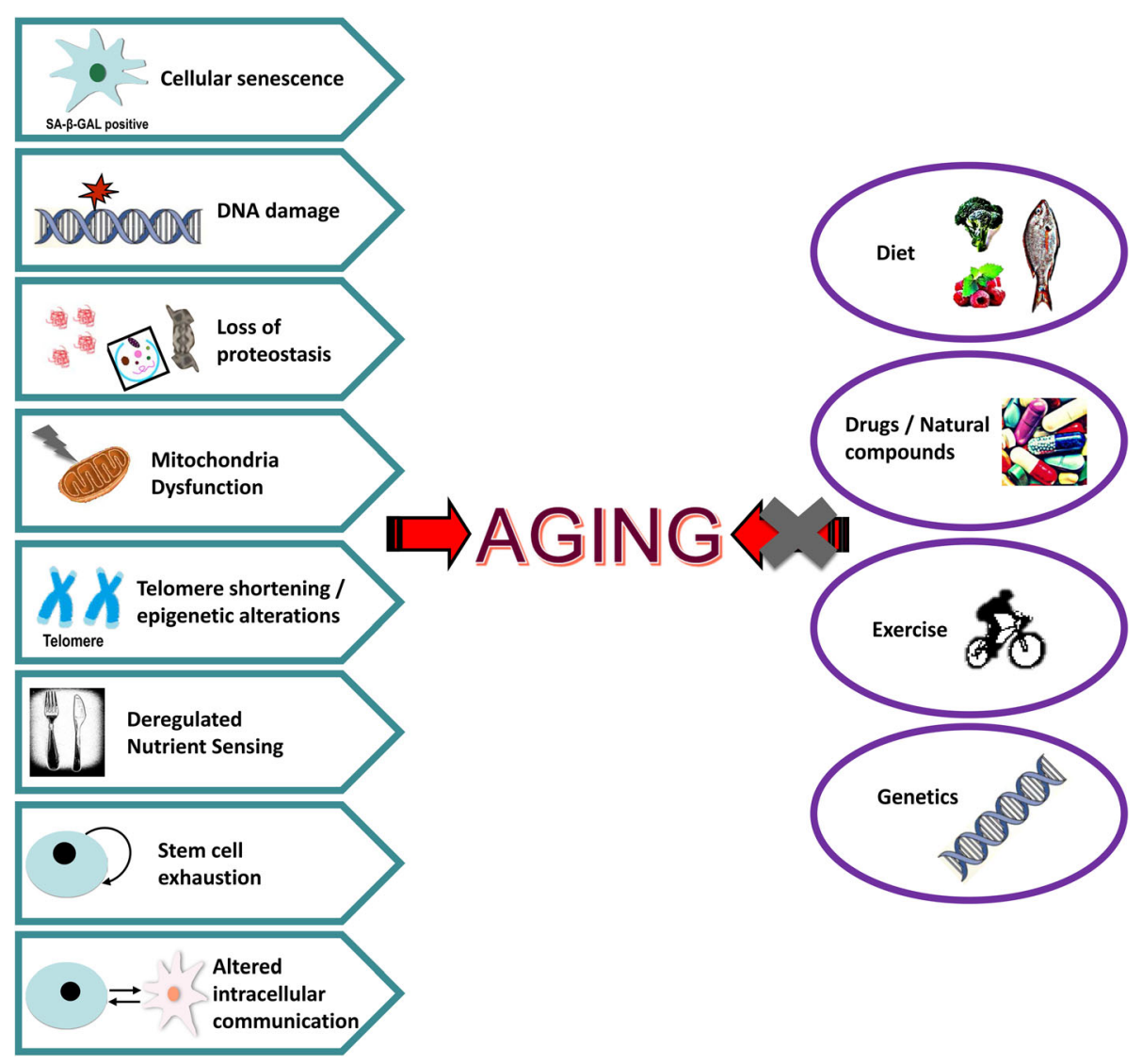

Fig. 2 The hallmarks of aging. Aging hallmarks are common molecular processes and phenotypic alterations that define cellular senescence and/ or systemic aging across evolution. The highly conserved aging traits may act independently or coordinately with exogenous or endogenous stress factors, including specific dietary habits. Given that neither genetic modifications nor caloric restriction can be applied in humans; the understanding of how nutrition alters genome (nutrigenomics) and consequently proteome expression patterns, is a critical parameter for the design of nutritional interventions aiming to increase healthy aging

instability, telomere attrition, epigenetic alterations, loss of proteostasis, deregulation of nutrient sensing/ signaling, mitochondrial dysfunction, cellular senescence, stem cell exhaustion, and alteration of intercellular communication [16, 17]. These hallmarks lead to a progressive loss of organismal integrity and homeodynamics, which eventually results in impaired cellular function and increased morbidity. As in all other metazoans, aging in Drosophila correlates with increased mortality rates, and it is also marked by decreased spontaneous movement and climbing speed, impaired memory, heart function, and reproductive capacity [18-21].

Nutrigenomics is a rapidly emerging research field that studies the changes induced on the genome by diet, and it thus considers the intersection of three topics, namely, health, diet, and genomics. Nutrigenomics can be mainly conducted through the various -omics techniques, which (among others) include microarrays or RNA-Seq analysis (transcriptomics) for the measurement of changes in mRNAs expression; proteomics that identify changes in polypeptides expression or in post-translational modifications; metabolomics that mainly focus on the study of metabolites with molecular weight less than $2000 \mathrm{Da}$, and also, epigenomics that measure the changes in the epigenome, i.e., the histone posttranslational modifications and/or the DNA methylation pattern. Given its versatility as an experimental model, Drosophila is widely used for -omics analyses, and it can therefore be used to conduct many types of nutrigenomic studies [22]. At a more advanced stage, nutrigenomic studies and the understanding of diet-disease relationships can be used for the development of personalized dietary and medicinal products.

Herein, we discuss the mechanistic connections between nutrition and aging in Drosophila, and how this model organism can be used (with possible limitations) to study the effect of different diets (including natural products and/or their derivatives) on higher metazoans longevity. Also, we summarize the nutritional interventions that promote healthy aging and/or longevity in flies. 


\section{Molecular links between nutrition and aging in Drosophila}

Deregulation of the cellular metabolic pathways and nutrient sensing is a major molecular modification that drives age-related damage responses from yeast to primates $[11,16]$. Organisms have developed numerous signaling pathways for nutrient sensing controlled by a highly regulated neuroendocrine system and characterized by excessive interorgan communication, in order to monitor nutrient availability and adjust their "real-time" nutritional status [23, 24]. Moreover, many research groups have highlighted the role of caloric intake or dietary supplementation in lifespan elongation at different model organisms [25-28]. Notably, insulin/insulin-like growth factor signaling (IIS) modules are significantly conserved among mammals and Drosophila (Fig. 3).

Towards the trend of direct gene-disease association, several genes of the Drosophila genome have been associated with age-related phenotypes arising from nutrient sensing or signaling deregulation. The vast majority of these genes are implicated in a wide range of cellular processes including cell growth and maintenance, metabolism, signal transmission, protein transport, cell communication, stress responses, responses to pathogens, immune responses, oogenesis, and fecundity [2931]. Typical examples of nutrients sensing/signaling genes that are implicated in Drosophila aging are Sirtuin 1 (Sirt1, also known as Sir2) [32], Insulin-like receptor $(\operatorname{InR})$ [33-35], the insulin-like receptor substrate
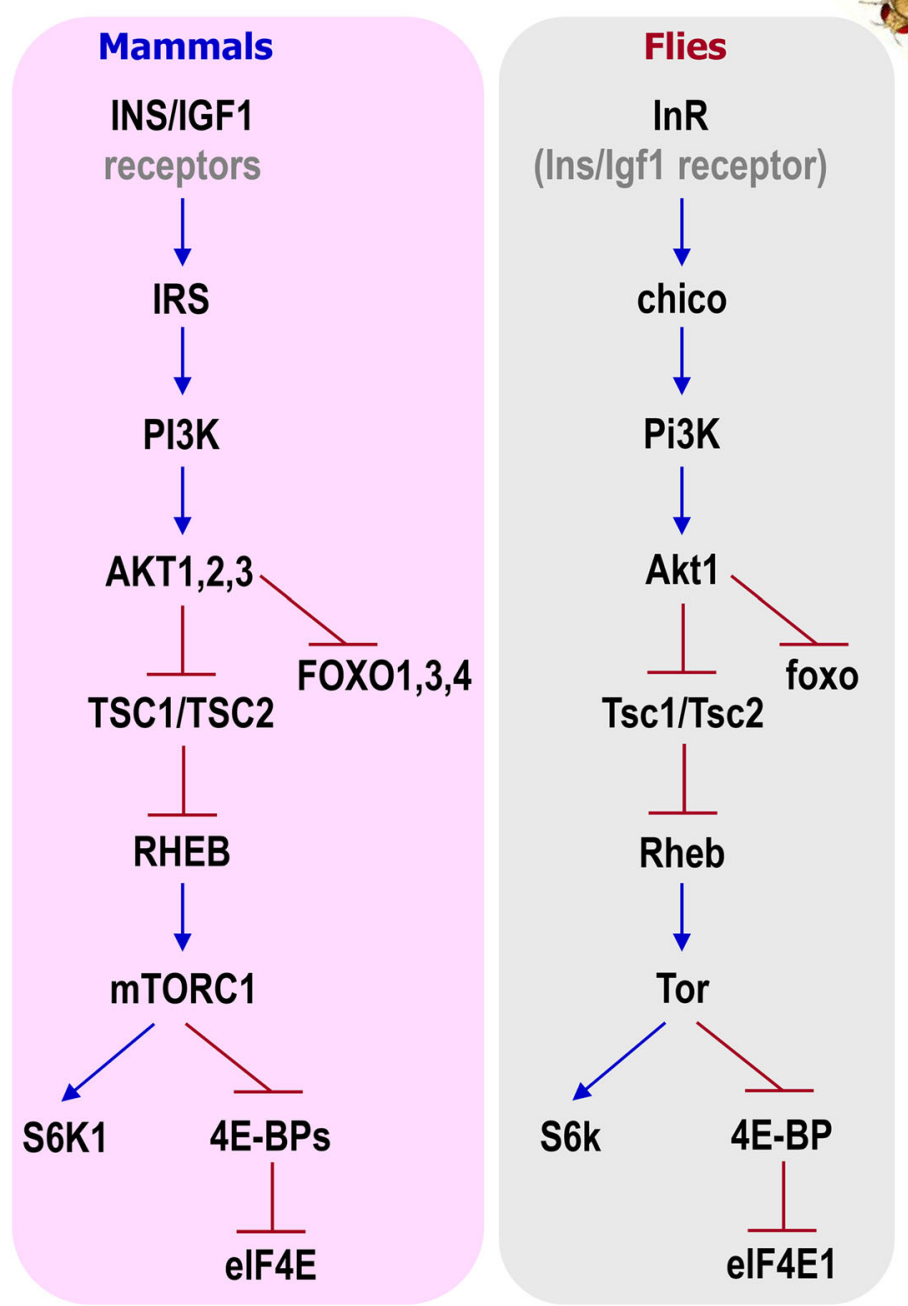

Fig. 3 Evolutionary conservation of the IIS pathway. Comparative depiction of the IIS pathway regulatory components and their evolutionary conservation in mammals and in Drosophila 
(chico) [36, 37], and the forkhead box, sub-group $\mathrm{O}$ (foxo) gene [38-40] (for a list of cited genes see, Additional file 1: Table S1).

Moreover, genetic manipulations of genes implicated in stress responses, regulation of proteome homeodynamics or energetic pathways and mitochondrial biogenesis, such as the heat shock proteins family (Hsps) [41, 42], the transcription factor cap-n-collar isoform-C ( $c n c C$, the ortholog of the mammalian nuclear factor, erythroid 2 like 2; Nrf2) [43, 44], the regulatory particle non-ATPase 11 (Rpn11) [45, 46], the autophagy-related 8a $(A \operatorname{tg} 8 a)[47,48]$ and spargel $(s r l$, the homolog of the mammalian peroxisome proliferator-activated receptor $($ PPAR $) Y$ coactivator-1; PGC-1) $[49,50]$ have revealed the functional involvement of these genes in regulating aging progression. Moreover, upon dietary manipulations, another fly gene suggested to influence several longevity traits is the stress-responsive gene methuselah (mth) [51, 52].

In line with these findings, molecular nutrient sensors like the AMP-activated protein kinase $\alpha$ subunit (AMPK $\alpha$ ) or sirtuins that encode a conserved family of nicotinamide adenine dinucleotide $\left(\mathrm{NAD}^{+}\right)$-dependent protein deacetylases; sense alternations in cellular energetics as they are affected by either the ratio of ADP/AMP to ATP or $\mathrm{NAD}^{+}$to NADH levels respectively, and therefore accordingly regulate catabolic and anabolic processes [53, 54]. The relative abundance of these cofactor pairs ensures metabolic homeostasis through the transcription of their downstream targets, which eventually modulate longevity [11]. In Drosophila, there are two major and highly conserved nutrient signaling pathways, namely, the IIS and the target of rapamycin (Tor) pathways [55], which are sensitive to changes in the cellular levels of glucose and amino acids respectively [56], and coordinately regulate each other [57]. Recent studies have shown that the function of this complex nutrient-sensing mechanism is (directly or indirectly) dependent on different types of diet and nutrients. More specifically, certain dietary interventions that lower the intensity of the signal by targeting modules of these two pathways could result in lifespan extension, improved neuromuscular activity, and preservation of cardiac health during aging [58].

Regardless of the thorough study of aging pathways associated with nutrition, the exact mechanism by which dietary interventions modulate longevity remains elusive. Most probably the coordinated action of a cluster of genes involved in stress responses to oxidants, IIS pathway, apoptosis, programmed autophagy, and the olfactory system, are responsible for the benefits of reduced nutritional input on healthspan and/or lifespan extension [59].

\section{The IIS pathway}

Association studies have shown that the main longevity-related genes involved in nutrient signaling are functionally conserved between the human and the Drosophila genome (Fig. 3) [60]. In mammals, energy homeostasis is tightly regulated by the antagonistic action of glucagon and the IIS pathway, as the main circulating energy sources are sugars. In flies, although glucose can be found in the hemolymph, trehalose (Treh) is the prevailing circulating sugar [61], which due to its chemical properties can transiently accumulate in the circulation at high levels without significant detrimental effects; unlike glucose in mammals that leads to hyperglycemia [62]. Nevertheless, overaccumulation or shortage of trehalose (Treh null mutants) may diminish the adaptation rates in nutrients poor environments [63].

As mentioned, the IIS pathway is highly conserved in the fruit fly, and Drosophila genome encodes eight insulin-like peptides (Ilps 1 to 8 ) with pleiotropic functions. Ilps are produced in distinct cell and tissue types at different developmental stages and bind to a single InR $[64,65]$. Ilp2, Ilp3, and Ilp5 are produced and secreted by insulin-producing cells (IPCs). IPCs are functional homologs of the human $\beta$-pancreatic cells and are located in the median neurosecretory cluster of flies' brain [64]. Upon secretion of the Ilps in the circulatory system (i.e. the hemolymph), a cascade of signal transduction (that employs several kinases), results in the suppression of the longevity-associated transcription factor foxo [66] (Fig. 3). The IIS pathway in Drosophila positively regulates fat storage and glycogen synthesis [63]. Upon low sugar levels in the hemolymph, the $\alpha$-pancreatic-like cells of the endocrine organ called corpora cardiaca activate the internal AMPK $\alpha$, which triggers the release of the glucagon-like adipokinetic hormone (Akh); a regulator of glycemia and lipid catabolism [61, 62, 67]. Akh binds to the adipocinetic hormone receptor (AkhR) in target tissues and triggers the conversion of stored glycogen and lipids to free energy [68]. Reduced activity of the IIS pathway is also associated with reduced growth and limited reproduction rates $[36,69]$. The fat body (analog of the mammalian liver and adipose tissue) is the main nutrient sensing organ, which remotely regulates the secretion of Ilps and longevity $[24,38,39]$. Genetic manipulations which suppress the IIS pathway, such as deletion of the Ilp2, 3 and 5 genes; overexpression of Ilp6 in the fat body or removal of neurosecretory cells from the Drosophila brain (IPCs ablation), have revealed the prevailing role of Ilps and Drosophila fat body as sensors of nutritional alternations [69-72]. Interestingly, the effects of IIS on longevity are apparently related to both metabolic and proliferative homeostasis since mild suppression of the IIS pathway in certain tissues or cells, which culminates 
in tissue/cell-specific foxo activation, or genetic induction of tissue/cell-specific foxo overexpression, result in increased longevity [73]. Moreover, in response to dietary sugars and fats unpaired 2 (upd2), the functional homolog to the mammalian leptin, is produced from the Drosophila fat body, which in turn increases Ilps release from IPCs [24]. Notably, the induction of the IIS pathway results in the activation of the major oxidant/electrophile sensitive transcription factor $\mathrm{cncC} / \mathrm{Nrf2}$, which triggers the transcriptional activation of antioxidant, proteostatic, and/or mitostatic genes [43, 74, 75]; consistently, $\mathrm{cncC} / \mathrm{Nrf} 2$ has also been proven to have a regulatory role in energy metabolism $[75,76]$. As the cncC/Nrf2 pathway is affected by the nutritional status, certain dietary interventions have the potential to modulate organisms' detoxification mechanisms, and therefore delay either the onset of age-related diseases or in vivo aging $[77,78]$.

\section{The Tor signaling pathway}

Sugars mainly serve as the cells' energy currency, while amino acids mostly serve as building blocks for protein synthesis. As mentioned above, the extra- or intracellular levels of amino acids are sensed by the Tor signaling pathway [79], which plays a vital role in balancing anabolic/catabolic rates, regulating cell growth and affecting longevity [80]. Tor signaling is conserved across evolution, while genetic studies have revealed that inhibition of Tor through nutrition ensures proteostasis and promotes longevity in Drosophila by suppressing the IIS pathway and increasing autophagic rates [81-83].

Central to the Tor signaling pathway is the Tor kinase that in mammals joins two multi-protein complexes, namely, the target of rapamycin complex 1 and 2 (TORC1, TORC2) [84]. TORC1 regulates mRNA translation and cell growth by two downstream molecules, namely, the ribosomal protein S6 kinase (S6k) and the cap-dependent translation initiator Thor (or 4E-BP) [85, 86]. TORC2 is involved in actin organization and upon activation, it triggers the phosphorylation of AKT serine/ threonine protein 1 (Akt1), the core kinase of the IIS pathway [82]. Several studies point out that the crosswiring between the two Tor-regulated signal transduction cascades is rather complex since the outcome of any intervention strongly depends on the intensity and the duration of the signal and/or the cell or tissue type [81, 87]. Positive upstream Tor regulators are major modules of the IIS pathway, such as growth factors, Pi3K21B (PI3K), and Akt1 [79], whereas the master nutrient sensors AMPK $\alpha$ and Sir2 negatively regulate Tor activity [88]. Upon nutrient sensing in the Drosophila fat body, Tor generates a humoral signal that modulates IIS and growth in peripheral tissues [56], suggesting that the two nutrient signaling pathways do not act independently but there is rather a coordinated action and eventually crosstalking.

\section{The effects of distinct nutritional interventions on healthy aging}

As the prevalence of obesity along with malnutrition rises worldwide, the interest of the scientific community has shifted towards the expansion of nutritional sciences and nutrigenomics $[22,89]$. The major aim across these lines of research is to fully address the mechanistic insights of the role of nutrition and nutrient-sensing pathways in promoting healthspan. Genome-wide association studies from human and animal models, the ongoing establishment of molecular mechanisms underlying diseases and the development of advanced analytical techniques for bioevaluation processes, point out the potential benefits of dietary manipulations as a novel anti-aging and/or disease-preventing strategy [2, 57, 89-91]. For example, the use of nutrient-dense foods improves the nutritional status and late-life disabilities of the elderly, the intermittent fasting lowers blood glucose in obese subjects, while caloric restriction extends lifespan and reduces genomic instability of some animal models, serving also as a potential anticancer approach with minimal side effects [92].

\section{Caloric restriction}

Up to date, the most effective and reproducible dietary intervention known to extend lifespan in several animal models including primates is caloric restriction (CR). CR refers to $\sim 20-40 \%$ reduction of food consumption [93, 94]. About half a century ago, it was reported for the first time in Drosophila that diluted medium prolongs both median and maximum lifespan [95, 96]. Like all living organisms, Drosophila needs to deploy macro- and micro-nutrients from its environment in order to maintain vital functions such as reproduction, movement, and self-preservation [97]. Although it is known that the nutrients which mostly affect longevity are carbohydrates, proteins, lipids, vitamins, and minerals, their exact mode of action is not well understood [98]; yet, studies in flies suggested that by restricting all dietary components or by simply reducing flies' protein intake, longevity can be extended by almost $50 \%[96,99]$.

Accordingly, further studies revealed the lifelong beneficial effects of feeding on specific nutrients such as low casein or low intermediate levels of methionine [100, 101], while other studies unveiled the lifespan-shortening effects of feeding on increased essential amino acids without the supplementation of carbohydrates, lipids, or vitamins, pointing out the negative impact of overconsumption [102]. Moreover, restriction of dietary protein suppresses the pathophysiological effects of in vivo organismal aging, 
reduces disease-associated risk factors, and delays the onset or progression of age-associated diseases [73]. Overall, reducing protein in relation to carbohydrate intake seems to be the key to longevity [103]; this fact contrasts previous studies which promoted $\mathrm{CR}$ as the key to enhanced longevity. Specifically, although CR indeed slows down biological aging [104], according to the CALERIE (Comprehensive Assessment of Long-Term Effects of Reducing Intake of Energy Clinical Trials; Gov. Identifier: NCT00427193, 93) clinical trial, it is difficult to enforce long-term $\mathrm{CR}$ on humans without detrimental effects on the quality of living [105]. Therefore, scientists have switched to pursuing either periodic dietary restriction (DR) or using small molecules that act as CR mimetics (CRMs), i.e., molecules which reproduce the systemic effects of chronic $\mathrm{CR}$ without limiting the amount of food $[106,107]$.

\section{Dietary restriction and caloric restriction mimetics}

In Drosophila rapid $(\sim 48 \mathrm{~h})$ DR alters the expression of several genes of the IIS/Tor pathways in order to achieve dietary balance [27, 108]. However, the exact molecular mechanism by which low-protein intake leads to lifespan extension needs further investigation, as genetic models prove that it engages both IIS-dependent and IISindependent mechanisms [109]. In support, long-lived chico mutants did not respond to optimal DR suggesting that lifespan extension is based on the IIS pathway [110], whereas foxo mutant flies were still sensitive to DR suggesting an IIS independent pathway [109].

On the other hand, Drosophila has also been employed as a platform to track molecules that could potentially mimic the beneficial effects of chronic CR, namely, CRMs. The best-studied types of CRMs in the fly model are those which act on specific downstream modules of the nutrients sensing or signaling pathways [107]. However, the use of CRMs does not always result in longevity extension. For instance, metformin, a well-known antidiabetic drug that triggers the activation of the nutrient sensor AMPK $\alpha$ and induces fat burn in the adipose tissue, does not confer lifespan elongation [111]. Administration of the Tor inhibitor rapamycin, known for its immunosuppressant properties, extends in a sex-dependent manner the lifespan of Drosophila flies with impaired energy regulation fed on a regular diet $[112,113]$. Furthermore, specific concentrations of the food supplement resveratrol promote longevity of flies fed with high lipids by activating the sirtuins network [114]. Another compound recognized as CRM is spermidine, which belongs to the polyamines group; reportedly, spermidine expands the lifespan of healthy Drosophila by inducing autophagy [115].

\section{High-fat and high-sugar diets}

Drosophila has also served as a model to study complex and progressive metabolic dysregulation during aging.
More specifically, high-fat (HFD) and/or sugar (HSD) diets have been used to trigger chronic metabolic diseases like obesity, hyperglycemia, insulin resistance, type II diabetes, and cardiomyopathies [91, 116, 117]. Either plant or animal-derived HFDs increase ectopic fat accumulation, promote insulin resistance, and over-activate the immune system, which in turn shortens lifespan [118-120]. Nevertheless, the effects of HFDs can be partially ameliorated by endurance training [121]. On the other hand, HSDs (containing 30\% sugars in the form of sucrose, glucose or fructose) affect Ilps production and lead to peripheral insulin resistance [122, 123]. Along with hyperglycemia and obesity, high-sugar content leads to proteotoxic stress conditions, such as increased endoplasmic reticulum stress, disruption of gut homeostasis, and progressive heart failure $[116,124$, 125]. There are several contradictory findings on the effects of HSDs on lifespan, as according to some studies HSDs suppress longevity, whereas others revealed that flies that have overcome HSDs toxicity during development or early adulthood, could extend their lifespan probably through metabolic reprogramming [126-128]. In addition, as reviewed recently [60] and according to the Nutritional Geometric Framework [103], a carbohydrate-rich diet could confer lifespan extension properties if it is accompanied by protein restriction [129]. Overall, these findings highlight that the most compelling aspect for a long healthy living is rather the dietary balance along with specific doses and not actually the caloric reduction (Fig. 4) [130].

\section{Dietary supplements for healthy aging and as interventions in age-related diseases}

Extracts from various sources of the biosphere (e.g., plants, microbes, or marine organisms) have been used for long as food supplements to promote health and/or longevity [131]. Recently, several natural products in the form of extracts or pure compounds have been shown to prolong lifespan and/or lower the risk of ageassociated diseases in model organisms by modulating the aforementioned nutrient sensing and signaling pathways. Mechanistically, the modulation of these pathways results in the activation of several cytoprotective processes including autophagy, antioxidant, proteostatic, and DNA repair responses [132-134].

\section{Plant extracts}

Many plant extracts including blueberries, apples, rosemary, ginger, aronia, pomegranate, nectarine, Rhodiola rosea, Platanus orientalis, asparagus, cocoa, and Curcuma longa have been shown to exert beneficial effects in aging studies in Drosophila. Blueberries and apples are fruits that possess a great antioxidant capacity due to their polyphenols [135]. Peng and colleagues [136] found 


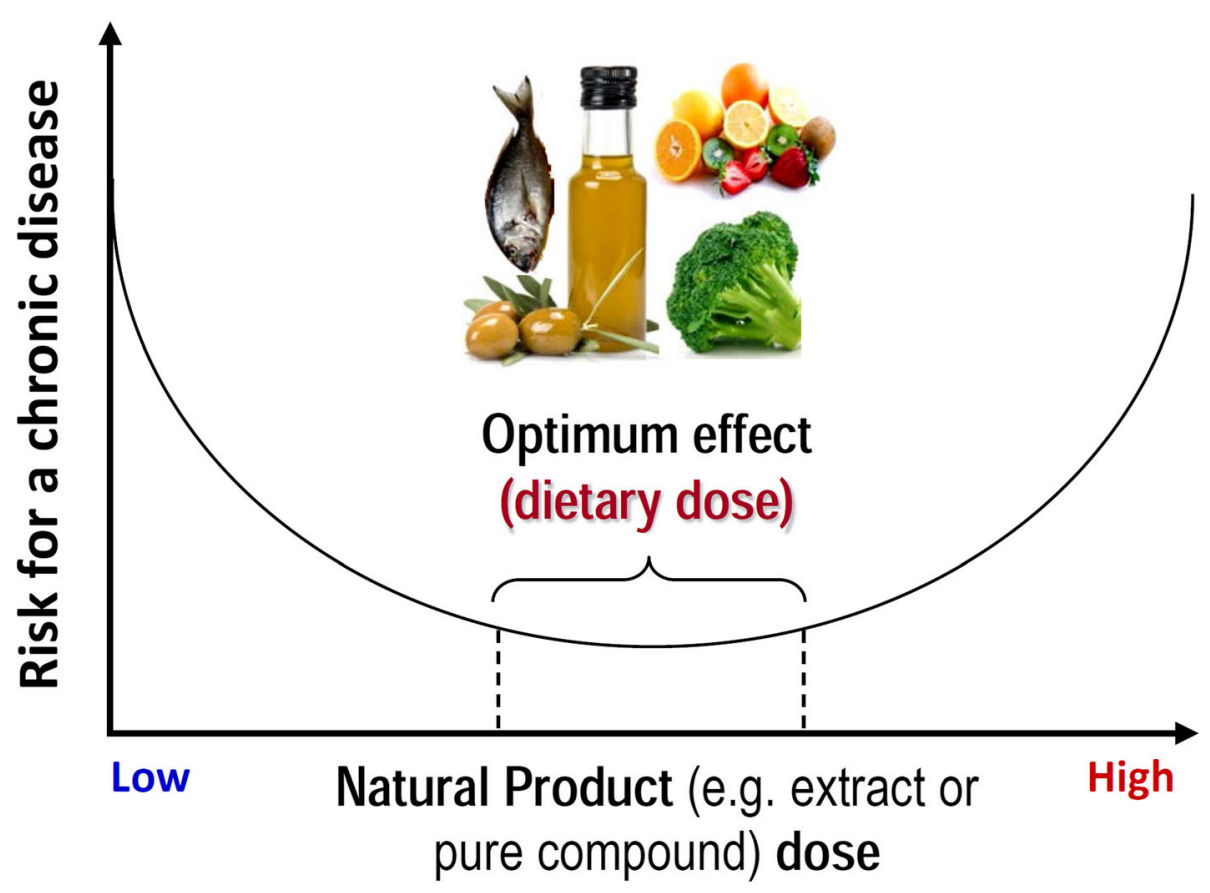

Fig. 4 The optimum effect of diet on aging and disease is usually around a narrow dose range. Dietary deficiencies or excess amounts of nutrients can lead to significant adverse effects on healthspan as the dose-response is not linear

that both blueberry $(5 \mathrm{mg} / \mathrm{ml})$ and apple polyphenol $(10$ $\mathrm{mg} / \mathrm{ml}$ ) extracts could significantly extend the mean lifespan of fruit flies by almost $10 \%$. The authors suggest that the lifespan-prolonging effect of these two extracts could be attributed to their interaction with superoxide dismutase $(S o d)$ and catalase $(C a t)$, which were upregulated, whereas mth and Rpn11, were found to be downregulated [136, 137]. Similarly, supplementation with a rosemary extract delayed aging in a dose-dependent manner; at $3 \mathrm{mg} / \mathrm{ml}$ this extract extended death time by $22.9 \%$, average lifetime by $17.49 \%$ and maximum longevity by $12.0 \%$. Moreover, it improved antioxidant enzymes activity, inhibited lipid peroxidation; significantly decreased malondialdehyde (MDA, a lipid oxidation product) content and increased the activities of Cat and Sod [138]. Another extract found to alter the expression patterns of Cat, Sod, and mth was an extract from ginger. Specifically, mRNA expression analysis in 30 days old flies fed with $1 \mathrm{mg} / \mathrm{ml}$ of ginger extract showed a significant upregulation of Sod and Cat genes, whereas downregulation of $m$ th was observed in flies fed with $2 \mathrm{mg} / \mathrm{ml}$ of the ginger extract as compared to flies fed with a standard diet. Supplementation of the culture medium with $1 \mathrm{mg} /$ $\mathrm{ml}$ and $2 \mathrm{mg} / \mathrm{ml}$ of ginger extract could prolong the mean lifespan by $6.49 \%$ and $7.30 \%$, and the maximum lifespan by $11.97 \%$ and $4.66 \%$, respectively. Ginger extract could also regulate the metabolism of amino acids, carbohydrates, and lipids, which indicates that the anti-aging effect is achieved by protecting mitochondrial function, coordinating the oxidant-antioxidant balance and ameliorating metabolic dysfunction [139].

Likewise, $2.5 \mathrm{mg} / \mathrm{ml}$ of Aronia extract was found to extend the mean lifespan of fruit flies by $18 \%$ and significantly improved the locomotor activity of both 10 and 40 days old flies. In 40 days old flies, ROS production was significantly lowered and accumulation of the lipid oxidation product MDA was markedly decreased. The extended longevity and improved locomotion were attributed to increased levels of the antioxidant enzymes Sod, Cat, and glutathione peroxidase (GPx) and to the induction of stress resistance genes, namely, heat shock protein 68 (Hsp68), lethal (2) essential for life [l(2)efl], and thioredoxin peroxidase 1 (Jafrac1) [140]. Furthermore, supplementation with $10 \%(v / v)$ pomegranate juice was shown to extend the lifespan of male flies by $18 \%$ and female flies by $8 \%$, when flies were raised separately, whereas a $19 \%$ lifespan increase was noted when male and females flies were cultured together. Moreover, researchers observed a simultaneous two-fold enhancement in fecundity and climbing activity, improved resistance to hydrogen peroxide $\left(\mathrm{H}_{2} \mathrm{O}_{2}\right)$ and paraquat (acute exposure) induced oxidative stress and enhanced resistance to Candida albicans infection [141]. Two other studies have identified a Rhodiola rosea extract (traditional western Ukraine medicinal adaptogen) as a culture medium additive that could extend lifespan. In the first study, flies fed with $5 \mathrm{mg} / \mathrm{ml}$ or $10 \mathrm{mg} / \mathrm{ml}$ of a $R$. rosea rhizome powder displayed a $14 \%$ to $17 \%$ increase 
in median lifespan; also, flies were physically more active and less sensitive to oxidative and heat stress compared to controls. All the aforementioned effects were more pronounced at middle-aged flies [142]. In addition, Schriner and colleagues [143] found that a $R$. rosea extract extends lifespan in both genders, yet exerting some sex-specific differences. In female flies, the expression levels of glycolytic and Sir2 genes along with NADH levels were downregulated, while in males the $R$. rosea extract downregulated the mitochondrial heat shock protein 22 (Hsp22) expression levels, provided no protection against heat stress and had no effect on heat shock protein $70(H s p 70)$ gene expression [143]. Furthermore, we recently reported that the extracts of the Platanus orientalis activated proteostatic mechanisms, e.g., proteasome and lysosomal cathepsins activity, ameliorated age-related phenotypes, and promoted Drosophila longevity by activating tissues' antioxidant responses [144].

Likewise, SC100, a preparation which consists of four herbal extracts containing Astragalus membranaceus root, Pterocarpus marsupium bark, pine bark oligo-proanthocyanidins, and L-theanine predicted to modulate the expression of many age- and stress-related genes and it extended the longevity of Drosophila flies under certain environmental conditions, such as housing size and population density [145]. Last but not the least, exposure to extracts from two commonly used Indian medicinal plants, namely, Curcuma longa (rhizome) and Emblica officinalis (fruit) could significantly increase flies' lifespan [146]. Thus, extracts obtained from plants provide a precious source of natural products that can improve healthspan and/or promote longevity.

\section{Plant-derived compounds}

Resveratrol is a stress-response lipophilic polyphenol produced by plants, which has been shown to extend lifespan in different organisms through its CRM properties. Supplementation of larval diet with resveratrol has been found to extend the longevity of both genders and increase locomotor activity in adult males. This effect was attributed to the increased activity of the Sod and Cat enzymes in both genders [147]. Moreover, resveratrol could extend the lifespan of female flies fed with HFDs. This was associated with the suppression of age-related pathways, by downregulation of antioxidant peroxiredoxins, insulin-like peptides, and several downstream targets of the Jun-kinase pathway involved in the oxidative stress response [114]. However, the effect of resveratrol on aging remains controversial since other studies showed that resveratrol supplementation was not able to extend mean, median, or maximum lifespan of male and female flies; also, the body composition of the flies remained largely unchanged, flies did not exhibit any improved stress response towards $\mathrm{H}_{2} \mathrm{O}_{2}$ exposure and the mRNA levels of antioxidant and longevity-related genes, including Sir2, spargel ( $\mathrm{srl} / \mathrm{PGC}$-1), and I'm not dead yet (indy) remained unchanged [148].

On the other hand, it was shown that dietary ursolic acid supplementation (a triterpenoid exhibiting potential anti-inflammatory, antimicrobial, and anti-obesity properties) significantly elongated the healthspan, lifespan, and climbing activity of male Drosophila, probably because it counteracts age-related deficits in muscle strength. The authors also showed upregulation of the srl/PGC-1 expression levels that triggered a metabolic shift without reducing fecundity or gut integrity. In addition, ursolic acid was also shown to affect the flies' microbiota which resulted in lifespan extension [149].

Many other compounds have also been found to improve aged phenotypes and healthspan in the fly. Specifically, alkylresorcinols (belonging to the family of phenolic lipids), along with prunetin (a dietary isoflavone with phytoestrogenic properties), extended the lifespan of Drosophila and improved climbing activity [150, 151]. Prunetin-fed males exhibited increased expression of Sir 2 by $22 \%$, AMPK $\alpha$ activation by $51 \%$ and elevated triglyceride levels by $29 \%$, whereas glucose levels were decreased by $36 \%$. As female flies are considered long-lived compared to males and exhibit higher triglyceride levels, it was thought that prunetin "feminizes" male flies via its estrogenic effects and therefore prolongs lifespan [151]. Finally, epigallocatechin-3-gallate (EGCG) derived from a green tea extract improved fitness and lifespan, as well as glucose metabolism and energy homeostasis in Drosophila; this green tea extract increased the mean and maximum ( 50\%) lifespan accompanied by improved fitness. These effects were followed by increased expression of $\mathrm{srl} /$ $P G C-1$, decreased glucose concentration, and inhibition of $\alpha$-amylase and of $\alpha$-glucosidase activity. Furthermore, EGCG was found to suppress the expression of Ilp5, phosphoenolpyruvate carboxykinase (Pepck), and upd2 genes which represent major regulators of glucose metabolism and systemic energy homeostasis [152].

\section{Fungal and marine extracts and compounds}

Ganoderma lucidum, Lentinula edodes, Agaricus blazei, and Auricularia auricula-judae are edible fungi that are used as traditional medicines in China and Philippines, as it is assumed that they have anti-aging properties and they also regulate the immune system to inhibit tumor cell growth [153, 154]. Supplementation of culture medium with $5 \mathrm{mg} / \mathrm{ml}$ extracts from $L$. edodes and $A$. blazei prolongs the lifespan of male and female flies by $6.03 \%$ and $2.69 \%$ respectively [153], while under heat stress and starvation an A. auricula-judae extract increased only the lifespan of female flies [154]. On the other hand, A. auricula extracts prolonged the lifespan 
of both genders, i.e., of male flies by $31.41 \%$ at $5 \mathrm{mg} / \mathrm{ml}$ and female flies by $16.85 \%$ at $20 \mathrm{mg} / \mathrm{ml}$ [153]. Finally, the extracts from G. lucidum extended the lifespan of male flies by $42.32 \%$ and of female flies by $29.24 \%$ at 80 $\mathrm{mg} / \mathrm{ml}$ and $5 \mathrm{mg} / \mathrm{ml}$, respectively. The dose and sex-dependent effects of edible mushroom extracts in promoting the longevity of Drosophila may be partially attributed to their ability to enhance antioxidant stress responses by modifying nutrient signaling pathways.

Indirubins are a family of bis-indoles naturally occurring in edible gastropod mollusks and plants, most of which are dual inhibitors of both cyclin-dependent kinases and glycogen synthase kinase-3 (GSK3; known in Drosophila as shaggy, sgg). GSK3/sgg regulates several cell functions, including survival, differentiation, proliferation, and metabolism. Accordingly, GSK3 has been implicated in various pathologies, including carcinogenesis, neurodegeneration, and diabetes. Our in vivo study of the hemisynthetic cell-permeable indirubin derivative 6-bromoindirubin-3'-oxime (6BIO) showed that $6 \mathrm{BIO}$ increases flies' healthspan by modulating bioenergetic pathways and activating cytoprotective modules [155]. Our results were further validated in human cells lines, suggesting a conserved action of 6BIO mechanisms [156].

\section{Dietary supplements intervention in age-related diseases} Drosophila melanogaster has been a valuable tool to unlock mechanisms underlying the onset and progression of many age-related diseases such as cancer, diabetes, neurodegenerative disorders, kidney, and immunological diseases [157]. The best-established screening assays have been developed and performed in Drosophila disease models with obese or neurodegenerative phenotypes [158-160], while considering the recent discovery and characterization of oncogenes and tumor suppressor genes in the fruit fly, there is a growing interest in screening tests to identify molecules with tumor growth inhibiting properties $[157,161]$.

As mentioned above DR, CRMs, healthy diets (such as the Mediterranean diet), and a healthy lifestyle have been proposed to promote energy balance and reduce the risk for cardiovascular disease and diabetes. Studies in Drosophila have revealed several extracts and pure compounds that could reduce fat accumulation and ectopic fat distribution associated with several pathological conditions. For example, Ilex paraguariensis extract was suggested to reduce the detrimental effects of HFDs in Drosophila [162], while the extract's metasaponins, phenolic compounds, and methylxanthines increased mean lifespan and reduced fat accumulation along with cholesterol levels [162]. Additionally, supplementation of HFDs with $4 \%$ nectarine increased lifespan and fecundity in female wild-type flies while it decreased the expression of several metabolic genes including the foxo transcriptional target Pepck and oxidative stress-related genes (e.g., peroxiredoxin). Moreover, nectarine extract improved the survival rates of female Sod1 mutant flies and reduced the levels of oxidative damage [163]. Supplementation of flies HFD with $3 \mathrm{mg} / \mathrm{ml}$ of rosemary extract elevated the enzymatic activities of Sod and Cat, increased the expression of $c n c C / N r f 2$; and reduced DNA lesions and MDA levels [164]. Furthermore, a recent study conducted in our lab revealed in the fly model the health beneficial properties of extra virgin olive oil (EVOO; a major component of the Mediterranean diet) on the pathological aspects of aberrant IIS activation [165], which results in increased accumulation of triglycerides in the flies' fat body; in significant inflammatory responses and reduced longevity [166]. Oleocanthal, a compound of EVOO, showed anti-inflammatory activity in mammalian cells [167]. In support by using a Drosophila model, which ubiquitously overexpresses the $\operatorname{In} R$ gene, we administrated $10 \mu \mathrm{g} / \mathrm{ml}$ oleocanthal (a compound isolated from EVOO) in the transgenic flies' medium, which in turn extended lifespan by reducing the toxic effects of IIS overactivation [165]. Moreover, oleocanthal exerts neuroprotective properties, and it has been suggested as a novel therapeutic strategy in neurodegeneration [168]. In addition, moderate supplementation of the flies' medium with cocoa increases flies average lifespan under normoxia, whereas under hyperoxia or in a $\mathrm{Cu} / \mathrm{Zn}$-Sod-deficient background, cocoa exhibits a strong antioxidant activity, significantly increasing lifespan [169].

Regarding neurodegeneration, several experimental fly models have been employed to test molecules that could potentially protect against neurotoxicity or delay the progressive loss of neuronal function. These diseasemimicking models have been constructed either by genetically manipulating the Drosophila genome to insert mutations or human disease-causing genes or by pharmacological induction of neurodegenerative diseases [170, 171]. Specifically, deficiency of the protein deacetylase 1 $(D J-1, \alpha$, or $\beta)$, mutation of the leucine-rich repeat kinase 2 (Lrrk, also known as LRRK2) or expression of the human synuclein alpha (SNCA or $h$-aS) in Drosophila leads in phenotypes that phenocopy Parkinson's disease (PD) pathology [172, 173]. Moreover, chronic exposure to paraquat has been recognized as an accelerator of PD manifestation along with lifespan and neuromuscular activity suppression [137]. Accordingly, several genetic manipulations in Drosophila, such as the expression of constructs encoding the human amyloid beta precursor protein $(A P P)$ and human beta secretase 1 (BACE1) or the overexpression of the human microtubule-associated protein tau $(M A P T)$ in the retina, have led to the generation of transgene models that imitate different aspects of the Alzheimer's disease (AD) pathology [174]. 
Moreover, mutations in RNA-binding proteins of Drosophila, such as in the transactive response DNAbinding protein-43 (TBPH, also known as TDP-43) resemble the onset of the neurodegenerative amyotrophic lateral sclerosis (ALS).

Based on the DJ-1-deficient model of PD, Sanz and colleagues [175] presented recently a screening study of a wide range of small molecules, which are either known to exert health beneficial properties or used to cure other conditions, to identify therapeutic candidates for PD. Compounds were mainly tested for their ability to improve PD's neuromuscular defects by measuring flies climbing activity $[175,176]$. This study suggested that supplementation of DJ-1-deficient flies' medium with dexrazoxane $(6.2 \mu \mathrm{M})$, pterostilbene $(78 \mu \mathrm{M})$, sodium phenylbutyrate $(0.54 \mathrm{mM})$, tocopherol $(1 \mathrm{mM})$, dalfampridine $(1 \mathrm{mM})$, methylene blue $(6 \mu \mathrm{M})$, or minocycline $(200 \mu \mathrm{M})$ resulted in improvement of the distinct mobility impairment of the PD phenotype. Moreover, most of the compounds mentioned above were found to diminish cytotoxicity of DJ-1-deficient human neuroblastoma cells [175]. Accordingly, Casani and colleagues [177] used the same PD fly model to test several vitamins. Vitamins, as described above, are among the most popular nutrients known to vitally contribute in maintaining energy balance [178]. Both the use of $1 \mathrm{mM}$ of a-tocopherol (a type of vitamin E) and $0.25 \mathrm{mg} / \mathrm{ml}$ ascorbic acid (vitamin $\mathrm{C}$ ) for 14 days resulted in downregulation of stress markers and extension of lifespan, probably by boosting Cat activity [177]. Furthermore, Faust and colleagues [179] tested the properties of celastrol on DJ-1 deficient flies. Celastrol is a triterpene known for its antioxidant properties, that is extracted from the root bark of the Triperygium wilfordii, a plant indigenous to southern China. The administration of $20 \mu \mathrm{g} / \mathrm{ml}$ celastrol for 20 days reduced the loss of dopaminergic neuron and brain's dopamine levels. Since degeneration of dopaminergic neuron is a hallmark of PD [180], the antioxidant and anti-inflammatory properties of celastrol sound rather promising [179]. Consistent studies have been also conducted on the Lrrk-mutated fly model of PD. The G2019S mutation in the Lrrk gene increases its pro-oxidative activity and inhibits endogenous peroxidases. The supplementation of flies' medium with $10 \mu \mathrm{M} / \mathrm{ml}$ of the strong kinase inhibitors piceatannol, thymoquinone, and esculetin reduced loss of dopaminergic neurons, oxidative load, and locomotor defects compared to weak kinase inhibitors, resulting in improved climbing scores and lifespan extension [181]. Moreover, supplementation of the Lrrk-mutated flies' medium with $0.05-0.1 \mu \mathrm{M}$ of lovastatin for 4 weeks activated the Akt1-cncC/Nrf2 axis and inhibited the activity of GSK3/sgg. Similarly, the $h-a S$ transgenic fly model of PD was employed to test the neuroprotective activity of
Cantella asiatica leaf extract [182]. The supplementation of flies' medium for $24 \mathrm{~h}$ with $0.25-1.0 \mu \mathrm{l} / \mathrm{ml}$ of the extract reduced PD symptoms by delaying the loss of neuromuscular activity and lowering oxidative stress.

The best example of pharmacologically induced experimental fly model to study neurodegeneration is the long-term administration of paraquat that accelerates PD development. Peng and colleagues [59, 137, 183] have exploited this pharmacological model to test the properties of several extracts. Administration of $10 \mathrm{mg} /$ $\mathrm{ml}$ of apple polyphenols extracts, $5 \mathrm{mg} / \mathrm{ml}$ of blueberry extract, or $30 \mathrm{mg} / \mathrm{ml}$ of black rice extract on the medium of flies chronically exposed to paraquat attenuated motor neuron degeneration along with early mortality. The authors attribute the beneficial activities of these extracts to their ability to interact with the expression of age-associated genes and antioxidant enzymes (see above) [59, 137, 183].

Curcumin and acacetin have been proposed to ameliorate the $\mathrm{AD}$ phenotype in several AD Drosophila models. More specifically, $0.01 \% w / w$ of curcumin supplementation resulted in increased healthspan and longevity of flies, while it reduced neurotoxicity by promoting amyloid fibril conversion and reduction of amyloid beta oligomeric species [184]. On the other hand, acacetin was proposed to rescue AD transgenic flies from developing motor abnormalities and decreased the number of amyloid plaques by inhibiting APP synthesis and decreasing BACE-1 activity [185].

Finally, the combined use of Mucuna pruriens $(0.1 \%$ $w / w)$ and Withania somnifera $(0.1 \% w / w)$ extracts in the medium of $T B P H$-mutated flies rescued the irregular locomotion and sleep deregulation. As proposed by Maccioni and colleagues [186], results hint towards a possible deregulation of some potassium channels in the $T B P H$-mutated model of ALS that might shed new light on future therapeutic strategies.

In conclusion, these studies support the notion that supplementation of flies' culture medium with specific natural products may either increase healthspan/lifespan and/or ameliorate some of the age-related diseases phenotypes. The beneficial effects of these dietary interventions are mainly attributed to the crosstalk of nutrient sensing or signaling modules with factors of the cellular stress-response pathways [132].

\section{Limitations of nutrition studies in Drosophila}

Drosophila is a well-investigated and highly tractable model organism employed in nutrition research and nutraceuticals discovery since, as mentioned above, it shares high homology with several human metabolism and disease-related genes. Consistently, several insights of the molecular mechanisms that affect in vivo aging have been identified by studying the effects of distinct 
dietary habits and/or components of the fruit fly diet, which have been further translated or verified in mammals. Still, several considerations should be thoroughly taken into account before interpreting and consequently translating the results of nutraceutical studies from flies to humans.

\section{The composition of diets and the dosage of nutraceuticals}

Several meta-analysis studies that tried to investigate the systemic effects of specific nutrients on healthspan and/ or lifespan extension in the fly model found it hard to compare studies from different laboratories that use different "standard" Drosophila mediums, which exact content is rarely reported in published research papers [97, 187]. Given the number of existing nutrients in a diet and their cross-interactions, along with the established fact that even the dilution of a single amino acid can eventually modify longevity, the lifespan variations obtained in studies conducted by different research groups on the same model organism is not surprising [91]. A way out to this issue could be the use of synthetic (chemically defined) diets, like a holistic medium described recently [188], which will make nutrients and drugs more available to flies. However, a major disadvantage of this approach would be the cost and the relatively complex preparation. Thus, a compelling solution for consistency of nutrition studies in model organisms, including Drosophila, is the detailed reporting of the nutritional ingredients of complex diets.

Likewise, in the case of functional foods and nutraceuticals, caution should be taken regarding dosage, since different concentrations of the same molecule can yield entirely different outcomes due to mild stress (Fig. 4), a process known as hormesis [189]. This is particularly highlighted by genetic studies in which sustained induced overactivation of stress or nutrient sensors, such as cncC/Nrf2, Tor, or foxo, could have either prolongevity or toxic effects, depending on the duration of the intervention and their expression levels $[76,132]$.

\section{Hurdles in interpreting results from dietary interventions in Drosophila}

Another critical aspect of dietary interventions in the fly is the major role of the Drosophila olfactory and gustatory systems in regulating longevity. It has been proven that mutations in the olfactory system have the ability to alter energy balance, increase stress-resistance, and promote longevity [190]. Furthermore, it was suggested that the ability of flies to taste regulates lifespan expectancy. Specifically, either taste inputs or gustatory cues affect longevity by modifying a wide range of biological functions [191]. Notably, other studies indicate that the administration of various dietary factors in Drosophila medium, such as plant-derived secondary metabolites, results in reduced food intake as they significantly affect the taste of the food due to sweetness, bitterness, and/or saltiness [2]. Food intake can also be disturbed by the acidity of the medium, as the $\mathrm{pH}$ of the culture medium directly affects flies feeding behavior and modifies parameters, such as gut microbial growth, which ultimately impact on survival [192]. In addition, since food dilution to achieve CR results in the consumption of greater amounts of the diluted medium [193] and the current methods on food intake focus mainly on estimating digestion rather than more significant parameters, such as nutrients absorption and assimilation, more compelling methods need to be developed [194].

Moreover, diet intervals of the early developmental stages have been shown to have a significant role in longevity of the adult. Specifically, it was showed that the larval fat cells are used as energy sources in the early adulthood of Drosophila flies [195]; additional studies highlight the importance of the protein source (yeast) quality in the diet of larvae and its beneficial effects on physiological processes of the adult Drosophila life [196]. In support, recent studies emphasize an inter- or trans-generational consequence of diet [197-200], and the differential impact that nutritional manipulations may have to depend on the gender. This is supported by the major gender-dependent differences in the communication of the gut-brain axis, the function and components of the neuroendocrine system, the sensitivity to IIS pathway, as well as in nutrient demand and utilization [201-203]. Last, but not least, inconsistency in the results of dietary interventions may also arise from variances in the age of the experimental models, as older flies tend to consume less (compared to young flies) food [91, 204]. Finally, since the gut-microbiota (derived from food intake) plays a key role in energy homeostasis of the fly host, it is worth mentioning that during aging the density of gut-microbes increases, whereas the composition of the microbes changes according to food intake [92].

\section{Concluding remarks}

Aging is a stochastic process and given that the doses of environmental stressors remain relatively stable during a given lifetime, it can be assumed that (excluding particular lifestyle habits, e.g., smoking) the biomolecules damage and the rate of aging are mainly affected by dietand metabolism-derived stressors. Considering also that aging is the major risk factor for human diseases like metabolic syndromes, neurodegeneration, and cancer, as well as that diet is in fact the only feasible life-lasting applicable "intervention" in humans, the use of model organisms is particularly critical towards our effort to understand how different dietary habits affect genome 


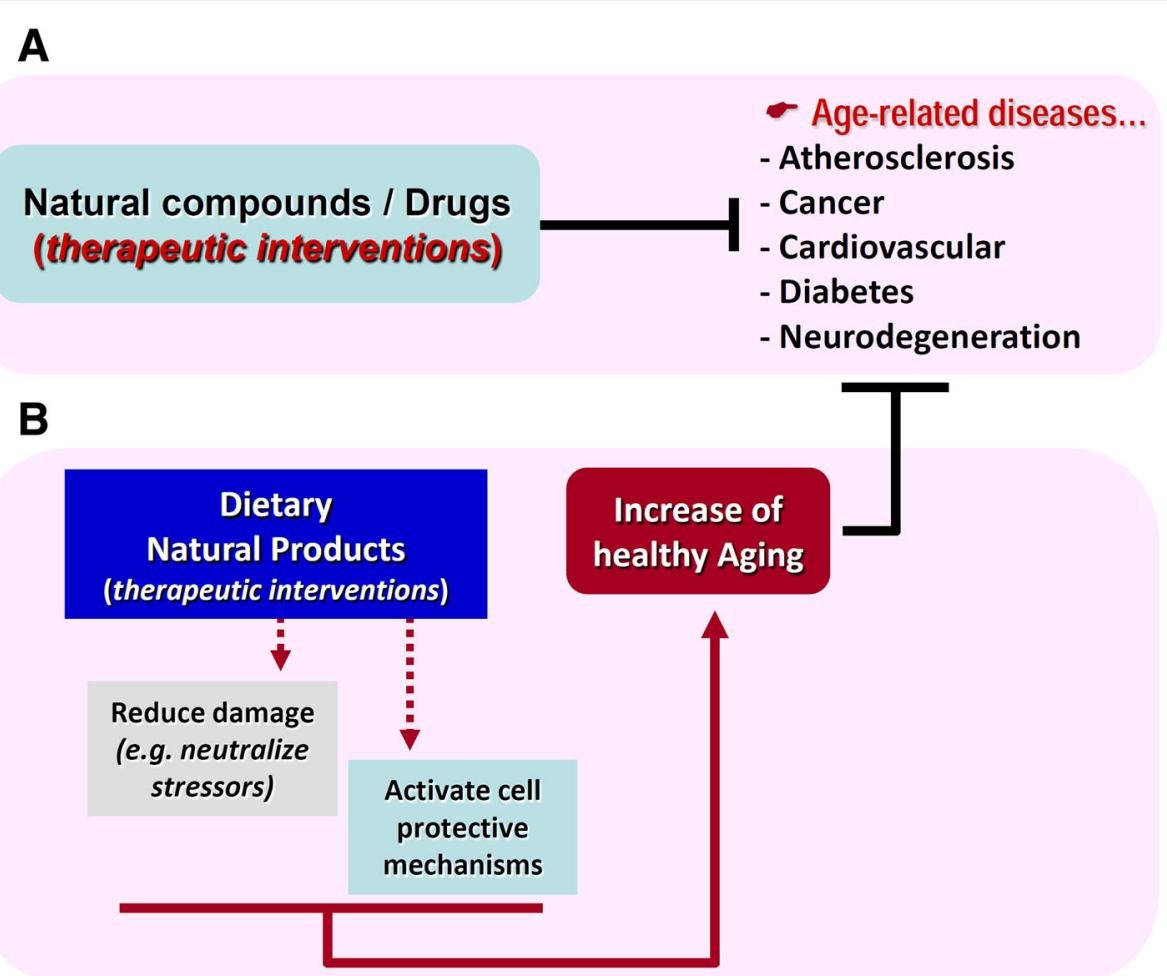

Fig. 5 Systemic dietary anti-aging interventions have the potential to also act as inhibitors of age-related diseases. a Current therapeutic approaches target individual diseases that occur in an aged cellular landscape characterized by high concentration of stressors and damaged biomolecules. b The identification of dietary interventions, e.g., specific diets enriched in bioactive natural compounds (or extracts) that either neutralize stressors or trigger a mild activation of cytoprotective mechanisms, will likely increase healthspan suppressing thus the appearance or delaying the onset of most age-related diseases

(nutrigenomics) and/or proteome, and for the isolation of natural products with the potential to be used in the foreseeable future as a comprehensive and surely cost-effective mean to increase healthspan and/ or lifespan.

Research in Drosophila has pioneered our efforts to understand developmental processes in higher metazoans and quite recently the fly has reappeared in the scene as a model organism for the study of molecular-cellular mechanisms that affect aging. Moreover, studies in Drosophila have started to elucidate critical parameters of the impact of diet or of the optimum doses of natural products (Fig. 4) on health outcome. Nonetheless, our attempt to promote advancement in nutrition science and nutrigenomics, and also to translate the research outcomes to humans, harbors several risks and unresolved issues. For instance, species-specific effects of nutritional manipulations should be carefully taken into consideration and, although Drosophila may be informative in new therapeutic discovery processes, it is necessary to have a well-defined hypothesis and a thorough perception of the fly's limitations, e.g., differences in the blood-brain barrier permeability or lack of adaptive immunity $[13,92]$, in order to achieve meaningful outcomes.

Yet, the numerous advantages of Drosophila as an alternative model in nutrigenomics, as well as in modeling diet-induced chronic age-related disorders, or the effects of nutrition on aging, will surely reveal new gene-disease interactions in response to diet, and thus new targets and therapeutics. We propose that analyses of the crosstalk and functional interactions of pathways controlling genomic responses to dietary interventions in model organisms can provide valuable preclinical insights on how systemic anti-aging interventions can act as potent inhibitors of age-related diseases (Fig. 5), elucidating potential therapeutic avenues against both aging and age-associated pathologies.

\section{Additional file}

Additional file 1: Table S1. List of genes. (PDF $75 \mathrm{~kb}$ )

\section{Abbreviations}

6BIO: 6-Bromoindirubin-3'-oxime; AD: Alzheimer's disease; Akh: Adipokinetic hormone; AkhR: Adipokinetic hormone receptor; ALS: Amyotrophic lateral 
sclerosis; AMPKa: AMP-activated protein kinase a subunit; Atg8a: Autophagyrelated 8a; Cat: Catalase; cncC: Cap-'n'-collar isoform-C; CR: Caloric restriction; CRM: Caloric restriction mimetic; DR: Dietary restriction;

EGCG: Epigallocatechin-3-gallate; EVOO: Extra virgin olive oil; foxo: Forkhead box, sub-group O; GSK3: Glycogen synthase kinase-3; $\mathrm{H}_{2} \mathrm{O}_{2}$ : Hydrogen peroxide; HFD: High-fat diet; HSD: High-sugar diet; Hsp: Heat shock protein; h-aS: Human synuclein alpha (SNCA); IIS: Insulin/insulin-like growth factor signaling; Ilps: Insulin-like peptides; Indy: I'm not dead yet; InR: Insulin-like receptor; IPCs: Insulin-producing cells; Lrrk: Leukine-rich repeat kinase; MDA: Malondialdehyde; mth: Methuselah; NAD: Nicotinamide adenine dinucleotide; Nrf2: Nuclear factor, erythroid 2 like 2; PD: Parkinson's disease; Pepck: Phosphoenolpyruvate carboxykinase; Rpn11: Regulatory particle nonATPase 11; S6k: Ribosomal protein S6 kinase; sgg: Shaggy; Sirt: Sirtuin; Sod: Superoxide dismutase; srl: Spargel; TBPH: Transactive response DNAbinding protein-43 homolog; Tor: Target of rapamycin; TORC1: Target of rapamycin complex 1; TORC2: Target of rapamycin complex 2; Treh: Trehalose; upd2: Unpaired 2

\section{Acknowledgements}

Not applicable.

\section{Funding}

IPT acknowledges funding from the EU project TASCMAR (EU-H2020/634674) and the Hellenic GSRT projects BIOIMAGING-GR (MIS 5002755) and PlantUpGR (MIS 5002803). ZE is a recipient of a PhD fellowship from the Hellenic Foundation for Research and Innovation (HFRI) under the HFRI PhD Fellowship grant (GA.1869). Maria Manola is a recipient of a PhD fellowship from the Hellenic State Scholarships Foundation [IKY; this research is COfinanced by Greece and the European Social Fund through the Operational Programme "Human Resources Development, Education and Lifelong Learning" in the context of the project "Strengthening Human Resources Research Potential via Doctorate Research" (MIS-5000432)].

\section{Availability of data and materials}

Not applicable.

\section{Authors' contributions}

All authors contributed to writing the manuscript. All authors read and approved the final manuscript.

\section{Ethics approval and consent to participate}

Not applicable.

\section{Consent for publication}

Not applicable.

\section{Competing interests}

The authors declare that they have no competing interests.

\section{Publisher's Note}

Springer Nature remains neutral with regard to jurisdictional claims in published maps and institutional affiliations.

\section{Received: 19 March 2019 Accepted: 10 April 2019}

\section{Published online: 02 May 2019}

\section{References}

1. Helfand SL, Rogina B. Genetics of aging in the fruit fly, Drosophila melanogaster. Annu Rev Genet. 2003;37:329-48.

2. Staats $\mathrm{S}$, Lüersen $\mathrm{K}$, Wagner AE, Rimbach G. Drosophila melanogaster as a versatile model organism in food and nutrition research. J Agric Food Chem. 2018;66(15):3737-53.

3. Chow CY, Reiter LT. Etiology of human genetic disease on the fly. Trends Genet. 2017;33(6):391-8.

4. Bellen $\mathrm{HJ}$, Yamamoto $\mathrm{S}$. Morgan's legacy: fruit flies and the functional annotation of conserved genes. Cell. 2015;163(1):12-4.

5. Venken KJ, Bellen HJ. Chemical mutagens, transposons, and transgenes to interrogate gene function in Drosophila melanogaster. Methods. 2014;68(1): $15-28$.

6. Brand AH, Perrimon N. Targeted gene expression as a means of altering cell fates and generating dominant phenotypes. Development. 1993;118(2):401-15.
7. Adams MD, Celniker SE, Holt RA, Evans CA, Gocayne JD, Amanatides PG et al. The genome sequence of Drosophila melanogaster. Science. 2000; 287(5461):2185-95.

8. Hales KG, Korey CA, Larracuente AM, Roberts DM. Genetics on the fly: a primer on the Drosophila model system. Genetics. 2015;201(3):815-42.

9. Lloyd TE, Taylor JP. Flightless flies: Drosophila models of neuromuscular disease. Ann N Y Acad Sci. 2010;1184:e1-20.

10. Gumeni S, Trougakos IP. Cross talk of proteostasis and mitostasis in cellular homeodynamics, ageing, and disease. Oxidative Med Cell Longev. 2016; 2016:4587691.

11. Piper MDW, Partridge L. Drosophila as a model for ageing. Biochim Biophys Acta - Mol Basis Dis. 2018;1864(9):2707-17.

12. Kennedy EM, Kornepati AV, Bogerd HP, Cullen BR. Partial reconstitution of the RNAi response in human cells using Drosophila gene products. RNA. 2017:23(2):153-60.

13. Pandey UB, Nichols CD. Human disease models in Drosophila melanogaster and the role of the fly in therapeutic drug discovery. Pharmacol Rev. 2011; 63(2):411-36.

14. Bilen J, Bonini NM. Drosophila as a model for human neurodegenerative disease. Annu Rev Genet. 2005;39:153-71.

15. Sang TK, Jackson GR. Drosophila models of neurodegenerative disease. NeuroRx. 2005;2(3):438-46.

16. López-Otín C, Blasco MA, Partridge L, Serrano M, Kroemer G. The hallmarks of aging. Cell. 2013;153(6):1194-217.

17. Gumeni S, Evangelakou Z, Gorgoulis VG, Trougakos IP. Proteome stability as a key factor of genome integrity. Int J Mol Sci. 2017;18(10).

18. Grotewiel MS, Martin I, Bhandari P, Cook-Wiens E. Functional senescence in Drosophila melanogaster. Ageing Res Rev. 2005;4(3):372-97.

19. Iliadi KG, Boulianne GL. Age-related behavioral changes in Drosophila. Ann N Y Acad Sci. 2010;1197:9-18.

20. Piazza N, Gosangi B, Devilla S, Arking R, Wessells R. Exercise-training in young Drosophila melanogaster reduces age-related decline in mobility and cardiac performance. PLoS One. 2009;4(6):e5886.

21. Reenan RA, Rogina B. Acquired temperature-sensitive paralysis as a biomarker of declining neuronal function in aging Drosophila. Aging Cell. 2008;7(2):179-86.

22. Ruden DM, De Luca M, Garfinkel MD, Bynum KL, Lu X. Drosophila nutrigenomics can provide clues to human gene-nutrient interactions. Annu Rev Nutr. 2005:25:499-522.

23. Chantranupong L, Wolfson RL, Sabatini DM. Nutrient-sensing mechanisms across evolution. Cell. 2015;161(1):67-83.

24. Rajan A, Perrimon N. Drosophila as a model for interorgan communication: lessons from studies on energy homeostasis. Dev Cell. 2011;21(1):29-31.

25. Ding F, Gil MP, Franklin M, Ferreira J, Tatar M, Helfand SL, Neretti N. Transcriptional response to dietary restriction in Drosophila melanogaster. J Insect Physiol. 2014;69:101-6.

26. May CM, Zwaan BJ. Relating past and present diet to phenotypic and transcriptomic variation in the fruit fly. BMC Genomics. 2017;18(1):640.

27. Whitaker R, Gil MP, Ding F, Tatar M, Helfand SL, Neretti N. Dietary switch reveals fast coordinated gene expression changes in Drosophila melanogaster. Aging. 2014;6(5):355-68.

28. Kim SI, Jung JW, Ahn YJ, Restifo LL, Kwon HW. Drosophila as a model system for studying lifespan and neuroprotective activities of plant-derived compounds. J Asia Pac Entomol. 2011:14(4):509-17.

29. Zhan M, Yamaza H, Sun Y, Sinclair J, Li H, Zou S. Temporal and spatial transcriptional profiles of aging in Drosophila melanogaster. Genome Res. 2007;17(8):1236-43.

30. Rose MR. Genetics of aging in Drosophila. Exp Gerontol. 1999;34(5):577-85 Review.

31. Tatar M. Reproductive aging in invertebrate genetic models. Ann N Y Acad Sci. 2010;1204:149-55.

32. Kusama S, Ueda R, Suda T, Nishihara S, Matsuura ET. Involvement of Drosophila Sirz-like genes in the regulation of lifespan. Genes Genet Syst. 2006:81(5):341-8.

33. Ismail MZ, Hodges MD, Boylan M, Achall R, Shirras A, Broughton SJ. The Drosophila insulin receptor independently modulates lifespan and locomotor senescence. PLoS One. 2015;10(5):e0125312.

34. Tanabe K, Itoh M, Tonoki A. Age-related changes in insulin-like signaling lead to intermediate-term memory impairment in Drosophila. Cell Rep. 2017;18(7):1598-605

35. Raj K, Sarkar S. Tissue-specific upregulation of Drosophila insulin receptor (InR) mitigates poly(Q)-mediated neurotoxicity by restoration of cellular transcription machinery. Mol Neurobiol. 2019;56(2):1310-29. 
36. Clancy DJ, Gems D, Harshman LG, Oldham S, Stocker H, Hafen E, et al. Extension of lifespan by loss of $\mathrm{CHICO}$, a Drosophila insulin receptor substrate protein. Science. 2001;292(5514):104-6.

37. Naganos S, Horiuchi J, Saitoe M. Mutations in the Drosophila insulin receptor substrate, $\mathrm{CHICO}$, impair olfactory associative learning. Neurosci Res. 2012;73(1):49-55.

38. Hwangbo DS, Gershman B, Tu MP, Palmer M, Tatar M. Drosophila dFOXO controls lifespan and regulates insulin signalling in brain and fat body. Nature. 2004;429(6991):562-6.

39. Giannakou ME, Goss M, Juenger MA, Ju MA, Hafen E, Leevers SJ, et al. Longlived Drosophila with over- expressed dFOXO in adult fat body. Science. 2004;305(5682):361.

40. Giannakou ME, Goss M, Jacobson J, Vinti G, Leevers SJ, Partridge L. Dynamics of the action of Dfoxo on adult mortality in Drosophila. Aging Cell. 2007:6(4):429-38.

41. Tatar M, Khazaeli AA, Curtsinger JW. Chaperoning extended life. Nature. 1997:390(6655):30

42. Minois N, Khazaeli AA, Curtsinger JW. Locomotor activity as a function of age and lifespan in Drosophila melanogaster overexpressing hsp70. Exp Gerontol. 2001;36(7):1137-53.

43. Tsakiri EN, Sykiotis GP, Papassideri IS, Terpos E, Dimopoulos MA, Gorgoulis VG, Bohmann D, Trougakos IP. Proteasome dysfunction in Drosophila signals to an Nrf2-dependent regulatory circuit aiming to restore proteostasis and prevent premature aging. Aging Cell. 2013;12(5):802-13.

44. Lewis KN, Mele J, Hayes JD, Buffenstein R. Nrf2, a guardian of healthspan and gatekeeper of species longevity. Integr Comp Biol. 2010;50(5):829-43.

45. Tonoki A, Kuranaga E, Tomioka T, Hamazaki J, Murata S, Tanaka K, Miura M. Genetic evidence linking age-dependent attenuation of the $26 \mathrm{~S}$ proteasome with the aging process. Mol Cell Biol. 2009;29(4):1095-106.

46. Tsakiri EN, Sykiotis GP, Papassideri IS, Gorgoulis VG, Bohmann D, Trougakos IP. Differential regulation of proteasome functionality in reproductive vs. somatic tissues of Drosophila during aging or oxidative stress. FASEB J. 2013; 27(6):2407-20.

47. Simonsen A, Cumming RC, Brech A, Isakson P, Schubert DR, Finley KD. Promoting basal levels of autophagy in the nervous system enhances longevity and oxidant resistance in adult Drosophila. Autophagy. 2008;4(2): 176-84.

48. Juhász G, Erdi B, Sass M, Neufeld TP. Atg7-dependent autophagy promotes neuronal health, stress tolerance, and longevity but is dispensable for metamorphosis in Drosophila. Genes Dev. 2007;21(23):3061-6.

49. Rera M, Bahadorani S, Cho J, Koehler CL, Ulgherait M, Hur JH, Ansari WS, Lo $T \mathrm{Jr}$, Jones DL, Walker DW. Modulation of longevity and tissue homeostasis by the Drosophila PGC-1 homolog. Cell Metab. 2011;14(5):623-34.

50. Mukherjee S, Basar MA, Davis C, Duttaroy A. Emerging functional similaritie and divergences between Drosophila Spargel/dPGC-1 and mammalian PGC 1 protein. Front Genet. 2014,5:216.

51. Lin YJ, Seroude L, Benzer S. Extended lifespan and stress resistance in the Drosophila mutant methuselah. Science. 1998;282(5390):943-6.

52. Gimenez LE, Ghildyal P, Fischer KE, Hu H, Ja WW, Eaton BA, Wu Y, Austad SN, Ranjan R. Modulation of methuselah expression targeted to Drosophila insulin-producing cells extends life and enhances oxidative stress resistance. Aging Cell. 2013;12(1):121-9.

53. Gowans GJ, Hardie DG. AMPK: a cellular energy sensor primarily regulated by AMP. Biochem Soc Trans. 2014;42(1):71-5

54. Wenzel U. Nutrition, sirtuins and aging. Genes Nutr. 2006;1(2):85-94.

55. Bettedi L, Foukas LC. Growth factor, energy and nutrient sensing signalling pathways in metabolic ageing. Biogerontology. 2017;18(6):913-29.

56. Koyama T, Mirth CK. Unravelling the diversity of mechanisms through which nutrition regulates body size in insects. Curr Opin Insect Sci. 2018:25:1-8.

57. Haigis MC, Yankner BA. The aging stress response. Mol Cell. 2010;40(2): 333-44

58. Partridge L, Alic N, Bjedov I, Piper MDW. Ageing in Drosophila: the role of the insulin/lgf and TOR signalling network. Exp Gerontol. 2011;46(5):376-81.

59. Peng C, Wang X, Chen J, Jiao R, Wang L, Li YM, et al. Biology of ageing and role of dietary antioxidants. Biomed Res Int. 2014;2014(831841):13.

60. Gáliková M, Klepsatel P. Obesity and aging in the Drosophila model. Int J Mol Sci. 2018;19:1896.

61. Kim SK, Rulifson EJ. Conserved mechanisms of glucose sensing and regulation by Drosophila corpora cardiaca cells. Nature. 2004;431:316-20.

62. Becker A, Schlöder $P$, Steele JE, Wegener $G$. The regulation of trehalose metabolism in insects. Experientia. 1996;52(5):433-9.
63. Yasugi T, Yamada T, Nishimura T. Adaptation to dietary conditions by trehalose metabolism in Drosophila. Sci Rep. 2017;7(1):2-10.

64. Nässel DR, Broeck J. Vanden. Insulin/IGF signaling in Drosophila and other insects: factors that regulate production, release and post-release action of the insulin-like peptides. Cell Mol Life Sci. 2016;73(2):271-90.

65. Slack C, Giannakou ME, Foley A, Goss M, Partridge L. dFOXO-independent effects of reduced insulin-like signaling in Drosophila. Aging Cell. 2011;10(5): 735-48.

66. Kannan K, Fridell YW. Functional implications of Drosophila insulin-like peptides in metabolism, aging, and dietary restriction. Front Physiol. 2013:4:288.

67. Gáliková M, Diesner M, Klepsatel P, Hehlert P, Xu Y, Bickmeyer I, et al. Energy homeostasis control in Drosophila adipokinetic hormone mutants. Genetics. 2015;201(2):665-83.

68. Braco JT, Gillespie EL, Alberto GE, Brenman JE, Johnson EC. Energydependent modulation of glucagon-like signaling in Drosophila via the AMP-activated protein kinase. Genetics. 2012;192(2):457-66.

69. Brogiolo W, Stocker H, Ikeya T, Rintelen F, Fernandez R, Hafen E. An evolutionarily conserved function of the Drosophila insulin receptor and insulin-like peptides in growth control. Curr Biol. 2001;11(4):213-21.

70. Grönke S, Clarke DF, Broughton S, Andrews TD, Partridge L. Molecular evolution and functional characterization of Drosophila insulin-like peptides. PLoS Genet. 2010;6(2). e1000857.

71. Broughton S, Piper MD, Ikeya T, Bass TM, Jacobson J, Driege Y, et al. Longer lifespan, altered metabolism, and stress resistance in Drosophila from ablation of cells making insulin-like ligands. Proc Natl Acad Sci. 2005;102(8): 3105-10.

72. Broughton SJ, Slack C, Alic N, Metaxakis A, Bass TM, Driege Y, Partridge L. DILP-producing median neurosecretory cells in the Drosophila brain mediate the response of lifespan to nutrition. Aging Cell. 2010;9(3):336-46.

73. Alic N, Partridge L. Death and dessert: nutrient signalling pathways and ageing. Curr Opin Cell Biol. 2011;23(6):738-43.

74. Sykiotis GP, Bohmann D. Stress-activated cap'n'collar transcription factors in aging and human disease. Sci Signal. 2010;3(112):re3.

75. Tsakiri EN, Gumeni S, Vougas V, Pendin D, Papassideri I, Daga A, et al. Proteasome dysfunction induces excessive proteome instability and loss of mitostasis that can be mitigated by enhancing mitochondrial fusion or autophagy. Autophagy. 2019. https://doi.org/10.1080/15548627.2019.1596477.

76. Tsakiri EN, Gumeni S, lliaki KK, Benaki D, Vougas K, Sykiotis GP, et al. Hyperactivation of Nrf2 increases stress tolerance at the cost of aging acceleration due to metabolic deregulation. Aging Cell. 2019;18(1):e12845.

77. Wedel S, Manola M, Jansen-dürr P. Targeting protein quality control mechanisms by natural products to promote healthy ageing. Molecules. 2018:13:1219.

78. Hodges RE, Minich DM. Modulation of metabolic detoxification pathways using foods and food-derived components: a scientific review with clinical application. J Nutr Metab. 2015:2015(760689):23.

79. Kim E. Mechanisms of amino acid sensing in mTOR signaling pathway. Nutr Res Pract. 2009;3(1):64.

80. Wullschleger $\mathrm{S}$, Loewith $\mathrm{R}$, Hall MN. TOR signaling in growth and metabolism. Cell. 2006:124(3):471-84.

81. Taylor RC, Dillin A. Aging as an event of proteostasis collapse. Cold Spring Harb Perspect Biol. 2011;3(5):1-17.

82. Vellai T, Takacs-Vellai K, Zhang Y, Kovacs AL, Orosz L, Müller F. Genetics: influence of TOR kinase on lifespan in C. elegans. Nature. 2003; 426(6967):620.

83. Kapahi P, Zid BM, Harper T, Koslover D, Sapin V, Benzer S. Regulation of lifespan in Drosophila by modulation of genes in the TOR signaling pathway. Curr Biol. 2004;14(10):885-90.

84. Bjedov I, Toivonen JM, Kerr F, Slack C, Jacobson J, Foley A, Partridge L. Mechanisms of life span extension by rapamycin in the fruit fly Drosophila melanogaster. Cell Metab. 2010;11(1):35-46.

85. Montagne J, Stewart MJ, Stocker H, Hafen E, Kozma SC, Thomas G, et al. Drosophila S6 kinase: a regulator of cell size. Science. 1999;285(5436):2126-9.

86. Um SH, D'Alessio D, Thomas G. Nutrient overload, insulin resistance, and ribosomal protein S6 kinase 1, S6K1. Cell Metab. 2006;3(6):393-402.

87. Zeng Z, Sarbassov dos D, Samudio IJ, Yee KW, Munsell MF, Ellen Jackson C, et al. Rapamycin derivatives reduce $\mathrm{MTORC} 2$ signaling and inhibit AKT activation in AML. Blood. 2007;109(8):3509-12 Epub 2006 Dec 19.

88. Berman AY, Motechin RA, Wiesenfeld MY, Holz MK. The therapeutic potential of resveratrol: a review of clinical trials. NPJ Precis Oncol. 2017;1:35. 
89. Shen B, Truong J, Helliwell R, Govindaraghavan S, Sucher NJ. An in vitro study of neuroprotective properties of traditional Chinese herbal medicines thought to promote healthy ageing and longevity. BMC Complement Altern Med. 2013;13:373.

90. Waltenberger B, Halabalaki M, Adamopoulos N, Fiebich BL, et al. Novel natural products for healthy ageing from the mediterranean diet and food plants of other global sources. MediHealth Project Mol. 2018;23(1097):1-16.

91. Owusu-Ansah E, Perrimon N. Modeling metabolic homeostasis and nutrient sensing in Drosophila: implications for aging and metabolic diseases. Dis Model Mech. 2014;7(3):343-50.

92. Fontana L, Partridge L. Promoting health and longevity through diet: from model organisms to humans. Cell. 2015;161(1):106-18.

93. Mattison JA, Roth GS, Beasley TM, Tilmont EM, Handy AM, Herbert RL, et al. Impact of caloric restriction on health and survival in rhesus monkeys: the NIA study. Nature. 2012;489(7415):318-21.

94. Klass MR. Aging in the nematode Caenorhabditis elegans: major biological and environmental factors influencing lifespan. Mech Ageing Dev. 1977;6(C): 413-29.

95. David J, Van Herrewege J, Fouillet P. Quantitative under-feeding of Drosophila: effects on adult longevity and fecundity. Exp Gerontol. 1971;6(3): 249-57.

96. Partridge L, Piper MDW, Mair W. Dietary restriction in Drosophila. Mech Ageing Dev. 2005;126(9 SPEC. ISS):938-50.

97. Piper MDW, Skorupa D, Partridge L. Diet, metabolism and lifespan in Drosophila. Exp Gerontol. 2005;40(11):857-62.

98. Lee D, Hwang W, Artan M, Jeong DE, Lee SJ. Effects of nutritional components on aging. Aging Cell. 2015;14:8-16.

99. Min KJ, Flatt T, Kulaots I, Tatar M. Counting calories in Drosophila diet restriction. Exp Gerontol. 2007:42(3):247-51.

100. Min KJ, Tatar M. Restriction of amino acids extends lifespan in Drosophila melanogaster. Mech Ageing Dev. 2006;127:643-6.

101. Troen AM, French EE, Roberts JF, Selhub J, Ordovas JM, Parnell LD, et al. Lifespan modification by glucose and methionine in Drosophila melanogaster fed a chemically defined diet. Age (Omaha). 2007;29(1):29-39.

102. Grandison RC, Piper MDW, Partridge L. UKPMC funders group restriction in Drosophila. Evolution (N Y). 2010;462(7276):1061-4.

103. Tatar M, Post S, Yu K. Nutrient control of Drosophila longevity. Trends Endocrinol Metab. 2014;25(10):509-17.

104. Belsky DW, Huffman KM, Pieper CF, Shalev I, Kraus WE, Anderson R. Change in the rate of biological aging in response to caloric restriction: Calerie biobank analysis. J Gerontol Ser A Biol Sci Med Sci. 2018;73(1):4-10.

105. Williamson DA, Martin CK, Roberts SB, Robinson L, Pieper CF, Das SK, et al. Effect of calorie restriction on mood, quality of life, sleep, and sexual function in healthy nonobese adults. JAMA Intern Med. 2016;176(6):743.

106. Brandhorst S, Choi IY, Wei M, Cheng CW, Sedrakyan S, Navarrete G, et al. A periodic diet that mimics fasting promotes multi-system regeneration, enhanced cognitive performance and healthspan Sebastian. Cell Metab. 2015;22(1):86-99.

107. Shintani H, Shintani T, Ashida H, Sato M. Calorie restriction mimetics: upstream-type compounds for modulating glucose metabolism. Nutrients. 2018;10:1821.

108. Efeyan A, Zoncu R, Sabatini DM. Amino acids and mTORC1: from lysosomes to disease mTOR in growth control. Trends Mol Med. 2013;18(9):524-33.

109. Min KJ, Yamamoto R, Buch S, Pankratz M, Tatar M. Drosophila lifespan control by dietary restriction independent of insulin-like signaling. Aging Cell. 2008;7(2):199-206.

110. Clancy DJ. Dietary restriction in long-lived dwarf flies. Science. 2002; 296(5566):319

111. Abrat OB, Storey JM, Storey KB, Lushchak VI. High amylose starch consumption induces obesity in Drosophila melanogaster and metformin partially prevents accumulation of storage lipids and shortens lifespan of the insects. Comp Biochem Physiol Part A Mol Integr Physiol. 2018; 215:55-62.

112. Pan H, Finkel T. Key proteins and pathways that regulate lifespan. J Biol Chem. 2017;292(16):6452-60.

113. Sun X, Komatsu T, Lim J, Laslo M, Yolitz J, Wang C, et al. Nutrientdependent requirement for SOD1 in lifespan extension by protein restriction in Drosophila melanogaster Xiaoping. Aging Cell. 2012;11(5): 783-93.

114. Wang C, Wheeler CT, Alberico T, Sun X, Seeberger J, Laslo M, et al. The effect of resveratrol on lifespan depends on both gender and dietary nutrient composition in Drosophila melanogaster. Age (Omaha). 2013;35(1): 69-81.

115. Fröhlich KU, Madeo F, Hartl R, Fahrenkrog B, Knauer H, Ring J, et al. Induction of autophagy by spermidine promotes longevity. Nat Cell Biol. 2009;11(11):1305-14.

116. Musselman L, Fink J, Grant A, Gatto J, Tuthill B II, Baranski T. A complex relationship between immunity and metabolism in Drosophila diet-induced insulin resistance. Mol Cell Biol. 2018;38(2):e00259-17.

117. Padmanabha D, Baker KD. Drosophila gains traction as a repurposed tool to investigate metabolism. Trends Endocrinol Metab. 2014;25(10):518-27.

118. Hong SH, Kang M, Lee KS, Yu K. High fat diet-induced TGF- $\beta /$ Gbb signaling provokes insulin resistance through the tribbles expression. Sci Rep. 2016;6:1-10.

119. Woodcock KJ, Kierdorf K, Pouchelon CA, Vivancos V, Dionne MS, Geissmann F. Macrophage-derived upd3 cytokine causes impaired glucose homeostasis and reduced lifespan in Drosophila fed a lipid-rich diet. Immunity. 2015; 42(1):133-44.

120. Heinrichsen ET, Haddad GG. Role of high-fat diet in stress response of Drosophila. PLoS One. 2012;7(8):3-10.

121. Wen D-T, Zheng L, Yang F, Li H-Z, Hou W-Q. Endurance exercise prevents high-fat-diet induced heart and mobility premature aging and dsir2 expression decline in aging Drosophila. Oncotarget. 2018;9(7):7298-311.

122. Rovenko BM, Perkhulyn NV, Gospodaryov DV, Sanz A, Lushchak OV, Lushchak VI. High consumption of fructose rather than glucose promotes a diet-induced obese phenotype in Drosophila melanogaster. Comp Biochem Physiol Part A Mol Integr Physiol. 2015;180:75-85.

123. Musselman L, Fink J, Ramachandran P, Hathiramani S, Cagan RL, Baranski T. A high-sugar diet produces obesity and insulin resistance in wild-type Drosophila. J Cell Sci. 2011:4:842-9.

124. Zhang $X$, Jin Q, Jin LH. High sugar diet disrupts gut homeostasis though JNK and STAT pathways in Drosophila. Biochem Biophys Res Commun. 2017:487(4):910-6

125. Na J, Cagan R. The Drosophila nephrocyte: back on stage. J Am Soc Nephrol. 2013;24(2):161-3.

126. Foley E, Galenza A, Hutchinson J, Hazes B, Campbell SD. Glucose modulates Drosophila longevity and immunity independent of the microbiota. Biol Open. 2016:5(2):165-73.

127. Lushchak OV, Gospodaryov DV, Rovenko BM, Yurkevych IS, Perkhulyn NV, Lushchak VI. Specific dietary carbohydrates differentially influence the lifespan and fecundity of Drosophila melanogaster. J Gerontol Ser A Biol Sci Med Sci. 2014;69(1):3-12

128. Reis T. Effects of synthetic diets enriched in specific nutrients on Drosophila development, body fat, and lifespan. PLoS One. 2016;11(1):1-12.

129. Le Couteur DG, Solon-Biet S, Cogger VC, Mitchell SJ, Senior A, de Cabo R, Raubenheimer D, Simpson SJ. The impact of low-protein high-carbohydrate diets on aging and lifespan. Cell Mol Life Sci. 2016;73(6):1237-52.

130. Skorupa DA, Dervisefendic A, Zwiener J, Pletcher SD. Dietary composition specifies consumption, obesity, and lifespan in Drosophila melanogaster. Aging Cell. 2008;7(4):478-90.

131. Weyrich LS, Duchene S, Soubrier J, Arriola L, Llamas B, Breen J, et al. Neanderthal behaviour, diet, and disease inferred from ancient DNA in dental calculus. Nature. 2017:544(7650):357-61.

132. Argyropoulou A, Aligiannis N, Trougakos IP, Skaltsounis A-L. Natural compounds with anti-ageing activity. Nat Prod Rep. 2013;30(11):1412-37.

133. Sklirou A, Papanagnou ED, Fokialakis N, Trougakos IP. Cancer chemoprevention via activation of proteostatic modules. Cancer Lett. 2018:413:110-21.

134. Martel J, Ojcius DM, Ko YF, Chang CJ, Young JD. Antiaging effects of bioactive molecules isolated from plants and fungi. Med Res Rev. 2019. https://doi.org/10.1002/med.21559

135. Shahidi F, Naczk M. Phenolics in food and nutraceuticals. Boca Raton: CRC Press; 2004. p. 132-210.

136. Peng C, Zuo Y, Kwan KM, Liang Y, Ma KY, Chan HY, Huang Y, Yu H, Chen ZY. Blueberry extract prolongs lifespan of Drosophila melanogaster. Exp Gerontol. 2012;47(2):170-8.

137. Peng C, Chan HY, Huang Y, Yu H, Chen ZY. Apple polyphenols extend the mean lifespan of Drosophila melanogaster. J Agric Food Chem. 2011;59(5):2097-106.

138. Zhang Y, Wen SP, Zhang ZS. Effects of rosemary extract on the lifespan and antioxidant system of Drosophila, 2012 international conference on nutrition and food sciences IPCBEE vol. 39. Singapore: IACSIT Press; 2012.

139. Zhou YZ, Xue LY, Gao L, Qin XM, Du GH. Ginger extract extends the lifespan of Drosophila melanogaster through antioxidation and ameliorating metabolic dysfunction. J Funct Foods. 2018;49:295-305. 
140. Jo AR, Imm JY. Effects of aronia extract on lifespan and age-related oxidative stress in Drosophila melanogaster. Food Sci Biotechnol. 2017;26(5): 1399-406.

141. Balasubramani SP, Mohan J, Chatterjee A, Patnaik E, Kukkupuni SK, Nongthomba U, Venkatasubramanian P. Pomegranate juice enhances healthy lifespan in Drosophila melanogaster: an exploratory study. Front Public Health. 2014;2:245

142. Gospodaryov DV, Yurkevych IS, Jafari M, Lushchak VI, Lushchak OV. Lifespan extension and delay of age-related functional decline caused by Rhodiola rosea depends on dietary macronutrient balance. Longev Healthspan. 2013;2(1):5.

143. Schriner SE, Lee K, Truong S, Salvadora KT, Maler S, Nam A, Lee T, Jafari M. Extension of Drosophila lifespan by Rhodiola rosea through a mechanism independent from dietary restriction. PLoS One. 2013;8(5):e63886.

144. Chatzigeorgiou S, Thai QD, Tchoumtchoua J, Tallas K, Tsakiri EN, Papassideri I, et al. Isolation of natural products with anti-ageing activity from the fruits of Platanus orientalis. Phytomedicine. 2017;33:53-61.

145. Villeponteau B, Matsagas K, Nobles AC, Rizza C, Horwitz M, Benford G, Mockett RJ. Herbal supplement extends lifespan under some environmental conditions and boosts stress resistance. PLoS One. 2015;10(4):e0119068.

146. Rawal S, Singh P, Gupta A, Mohanty S. Dietary intake of Curcuma longa and Emblica officinalis increases lifespan in Drosophila melanogaster. Biomed Res Int. 2014;2014:910290.

147. Chandrashekara KT, Shakarad MN. Aloe vera or resveratrol supplementation in larval diet delays adult aging in the fruit fly, Drosophila melanogaster. J Gerontol A Biol Sci Med Sci. 2011;66(9):965-71.

148. Staats S, Wagner AE, Kowalewski B, Rieck FT, Soukup ST, Kulling SE, Rimbach $G$. Dietary resveratrol does not affect lifespan, body composition, stress response, and longevity-related gene expression in Drosophila melanogaster. Int J Mol Sci. 2018;19(1):E223.

149. Staats S, Wagner AE, Lüersen K, Künstner A, Meyer T, Kahns AK, Derer S, Graspeuntner S, Rupp J, Busch H, Sina C, Ipharraguerre IR, Rimbach G. Dietary ursolic acid improves healthspan and lifespan in male Drosophila melanogaster. Biofactors. 2019;45(2):169-86.

150. Kayashima Y, Katayanagi Y, Tanaka K, Fukutomi R, Hiramoto S, Imai S. Alkylresorcinols activate SIRT1 and delay ageing in Drosophila melanogaster. Sci Rep. 2017:7:43679.

151. Piegholdt S, Rimbach G, Wagner AE. The phytoestrogen prunetin affects body composition and improves fitness and lifespan in male Drosophila melanogaster. FASEB J. 2016;30(2):948-58.

152. Wagner AE, Piegholdt S, Rabe D, Baenas N, Schloesser A, Eggersdorfer M, et al. Epigallocatechin gallate affects glucose metabolism and increases fitness and lifespan in Drosophila melanogaster. Oncotarget. 2015;6(31):30568-78.

153. Huang M, Liu J, Zhang S, Mei X, Yang X. Effects of bioactive extracts from four edible mushrooms on the lifespan of Drosophila melanogaster. Mycology. 2011;2(1):54-8.

154. Romero JJ, Ramos MRR, Tantengco OAG, Medina PMB. Sex differences in the effects of Auricularia auricula-judae ethanolic extracts on the lifespan of Drosophila melanogaster during stress and non-stress conditions. J Appl Pharm Sci. 2018;11:087-94.

155. Tsakiri EN, Gaboriaud-Kolar N, Iliaki KK, Tchoumtchoua J, Papanagnou ED, Chatzigeorgiou S, et al. The indirubin derivative 6-bromoindirubin-3'-oxime activates proteostatic modules, reprograms cellular bioenergetic pathways, and exerts antiaging effects. Antioxid Redox Signal. 2017;27(14):1027-47.

156. Sklirou AD, Gaboriaud-Kolar N, Papassideri I, Skaltsounis AL, Trougakos IP. 6bromo-indirubin-3'-oxime (6BIO), a glycogen synthase kinase-3 $\beta$ inhibitor, activates cytoprotective cellular modules and suppresses cellular senescence-mediated biomolecular damage in human fibroblasts. Sci Rep. 2017;7(1):11713

157. Strange K. Drug discovery in fish, flies, and worms. ILAR J. 2016;57(2):133-43.

158. Wang L, Hagemann TL, Messing A, Feany MB. An in vivo pharmacological screen identifies cholinergic signaling as a therapeutic target in glial-based nervous system disease. J Neurosci. 2016:36(5):1445-55.

159. Seguin A, Monnier V, Palandri A, Bihel F, Rera M, Schmitt M, et al. A yeast/ Drosophila screen to identify new compounds overcoming frataxin deficiency. Oxidative Med Cell Longev. 2015;2015:565140.

160. Chang S, Bray SM, Li Z, Zarnescu DC, He C, Jin P, et al. Identification of small molecules rescuing fragile $X$ syndrome phenotypes in Drosophila. Nat Chem Biol. 2008:4(4):256-63.

161. Yadav AK, Srikrishna S, Gupta SC. Cancer drug development using Drosophila as an in vivo tool: from bedside to bench and back. Trends Pharmacol Sci. 2016;37(9):789-806.
162. Colpo AC, Lima ME, Da Rosa HS, Leal AP, Colares CC, Zago AC, et al. Ilex paraguariensis extracts extend the lifespan of Drosophila melanogaster fed a high-fat diet. Brazilian J Med Biol Res. 2018;51(2):e6784.

163. Boyd O, Weng P, Sun X, Alberico T, Laslo M, Obenland DM, et al. Nectarine promotes longevity in Drosophila melanogaster. Free Radic Biol Med. 2011; 50(11):1669-78.

164. Wang HL, Sun ZO, Rehman RU, Wang H, Wang YF, Wang H. Rosemary extract-mediated lifespan extension and attenuated oxidative damage in Drosophila melanogaster fed on high-at diet. J Food Sci. 2017;82(4):1006-11.

165. Nikou T, Liaki V, Stathopoulos P, Sklirou AD, Tsakiri EN, Jakschitz T, et al. Comparison survey of EVOO polyphenols and exploration of healthy agingpromoting properties of oleocanthal and oleacein. Food Chem Toxicol. 2019:125:403-12.

166. Di Angelo JR, Bland ML, Bambina S, Cherry S, Birnbaum MJ. The immune response attenuates growth and nutrient storage in Drosophila by reducing insulin signaling. Proc Natl Acad Sci U S A. 2009;106(49):20853-8.

167. Scotece M, Gómez R, Conde J, Lopez V, Gómez-Reino JJ, Lago F, et al. Further evidence for the anti-inflammatory activity of oleocanthal: inhibition of MIP-1a and IL-6 in $\mathbf{J 7 7 4}$ macrophages and in ATDC5 chondrocytes. Life Sci. 2012;91(23-24):1229-35.

168. Abuznait AH, Oosa H, Busnena BA, El Sayed KA, Kaddoumi A. Olive-oilderived oleocanthal enhances $\beta$-amyloid clearance as a potential neuroprotective mechanism against Alzheimer's disease: in vitro and in vivo studies. ACS Chem Neurosci. 2013;4(6):973-82.

169. Bahadorani S, Hilliker AJ. Cocoa confers lifespan extension in Drosophila melanogaster. Nutr Res. 2008;28(6):377-82.

170. McGurk L, Berson A, Bonini NM. Drosophila as an in vivo model for human neurodegenerative disease. Genetics. 2015;201(2):377-402.

171. Lu B, Vogel H. Drosophila models of neurodegenerative diseases. Annu Rev Pathol. 2009:4:315-42.

172. Shendelman S, Jonason A, Martinat C, Leete T, Abeliovich A. DJ-1 is a redoxdependent molecular chaperone that inhibits a-synuclein aggregate formation. PLoS Biol. 2004;2(11):e362.

173. Langston RG, Rudenko IN, Cookson MR. The function of orthologues of the human Parkinson's disease gene LRRK2 across species: implications for disease modeling in preclinical research. Biochem J. 2016:473(3):221-32.

174. Moloney A, Sattelle DB, Lomas DA, Crowther DC. Alzheimer's disease: insights from Drosophila melanogaster models. Trends Biochem Sci. 2010; 35(4):228-35.

175. Sanz FJ, Solana-Manrique C, Munoz-Soriano V, Calap-Quintana P, Molto MD Paricio N. Identification of potential therapeutic compounds for Parkinson's disease using Drosophila and human cell models. Free Radic Biol Med. 2017; 108:683-91.

176. Rogers G, Davies D, Pink J, Cooper P. Parkinson's disease: summary of updated NICE guidance. BMJ. 2017;358:j1951.

177. Casani S, Gómez-Pastor R, Matallana E, Paricio N. Antioxidant compound supplementation prevents oxidative damage in a Drosophila model of Parkinson's disease. Free Radic Biol Med. 2013;61:151-60.

178. Khan S, Jyoti S, Naz F, Shakya B, Rahul, Afzal M, Siddique YH. Effect of Lascorbic acid on the climbing ability and protein levels in the brain of Drosophila model of Parkinson's disease. Int J Neurosci. 2012;122(12):704-9.

179. Faust K, Gehrke S, Yang Y, Yang L, Beal FM, Lu B. Neuroprotective effects of compounds with antioxidant and anti-inflammatory properties in a Drosophila model of Parkinson's disease. BMC Neurosci. 2009;10:109.

180. Lindvall O. Dopaminergic neurons for Parkinson's therapy. Nat Biotechnol. 2012;30(1):56-8

181. Angeles DC, Ho P, Dymock BW, Lim KL, Zhou ZD, Tan EK. Antioxidants inhibit neuronal toxicity in Parkinson's disease-linked LRRK2. Ann Clin Transl Neurol. 2015;3(4):288-94

182. Siddique $\mathrm{YH}, \mathrm{Naz}$ F, Jyoti S, Fatima A, Khanam S, Rahul, et al. Effect of Centella asiatica leaf extract on the dietary supplementation in transgenic Drosophila model of parkinson's disease. Parkinsons Dis. 2014:2014:11.

183. Zuo Y, Peng C, Liang Y, Mai K, Yu H, Chan H, et al. Black rice extract extends the lifespan of fruit flies. Food Funct. 2012:3:1271-127.

184. Caesar I, Jonson M, Nilsson KPR, Thor S, Hammarström P. Curcumin promotes a-beta fibrillation and reduces neurotoxicity in transgenic Drosophila. PLoS One. 2012;7(2):e31424.

185. Wang $X$, Perumalsamy $H$, Kwon HW, Na Y-E, Ahn Y-J. Effects and possible mechanisms of action of acacetin on the behavior and eye morphology of Drosophila models of Alzheimer's disease. Sci Rep. 2015. 5:16127. 
186. Maccioni R, Setzu MD, Talani G, Solari P, Kasture A, Sucic S, et al. Standardized phytotherapic extracts rescue anomalous locomotion and electrophysiological responses of TDP-43 Drosophila melanogaster model of ALS. Sci Rep. 2018;8(1):1-14.

187. Lüersen K, Röder T, Rimbach G. Drosophila melanogaster in nutrition research - the importance of standardizing experimental diets. Genes Nutr. 2019;14:3.

188. Piper MDW, Blanc E, Leitão-Gonçalves R, Yang M, He X, Linford NJ, et al. A holidic medium for Drosophila melanogaster. Nat Methods. 2014;11(1):100-5.

189. Rattan SIS. Hormesis in aging. Ageing Res Rev. 2008;7(1):63-78.

190. Libert S, Zwiener J, Chu X, VanVoorhies W, Roman G, Pletcher SD. Regulation of Drosophila lifespan by olfaction and food-derived odors. Science. 2007;315(5815):1133-7.

191. Chandra R, Ostojic I, Chan T, Alcedo J, Waterson MJ, Boll W, et al. Positive and negative gustatory inputs affect Drosophila lifespan partly in parallel to dFOXO signaling. Proc Natl Acad Sci. 2014;111(22):8143-8.

192. Deshpande SA, Yamada R, Mak CM, Hunter B, Obando AS, Hoxha S, et al. Acidic food pH increases palatability and consumption and extends Drosophila lifespan. J Nutr. 2015;145(12):2789-96.

193. Carvalho GB, Kapahi P, Benzer S. Compensatory ingestion upon dietary restriction in Drosophila melanogaster. Nat Methods. 2005;2(11):813-5.

194. Holl A, Maydt D. Epistemological foundations of requirements engineering. Enterp Bus Manag A Handb Educ Consult Pract. 2007;11(5):31-58.

195. Davies LR, Schou MF, Kristensen TN, Loeschcke V. Linking developmental diet to adult foraging choice in Drosophila melanogaster. J Exp Biol. 2018; 221:jeb175554.

196. Grangeteau C, Yahou F, Everaerts C, Dupont S, Farine JP, Beney L, et al. Yeast quality in juvenile diet affects Drosophila melanogaster adult life traits. Sci Rep. 2018;8(1):1-9.

197. Öst A, Lempradl A, Casas E, Weigert M, Tiko T, Deniz M, et al. Paternal diet defines offspring chromatin state and intergenerational obesity. Cell. 2014; 159(6):1352-64.

198. Stegemann R, Buchner DA. Transgenerational inheritance of metabolic disease. Semin Cell Dev Biol. 2015;43:131-40.

199. Guida MC, Birse RT, Dall'Agnese A, Toto PC, Diop SB, Mai A, et al. Intergenerational inheritance of high fat diet-induced cardiac lipotoxicity in Drosophila. Nat Commun. 2019:10(1):193.

200. Manola M, Tsakiri E, Trougakos I. Alterations in organismal physiology, impaired stress resistance and accelerated aging in Drosophila flies adapted to multigenerational proteome instability. Oxidative Med Cell Longev. 2019; (in press).

201. Westfall S, Lomis N, Prakash S. Longevity extension in Drosophila through gut-brain communication. Sci Rep. 2018;8:8362.

202. Magwere T, Chapman T, Partridge L. Sex differences in the effect of dietary restriction on lifespan and mortality rates in female and male Drosophila melanogaster. J Gerontol Ser A Biol Sci Med Sci. 2004;59(1):B3-9.

203. Ribeiro C, Dickson BJ. Sex peptide receptor and neuronal TOR/S6K signaling modulate nutrient balancing in Drosophila. Curr Biol. 2010;20(11):1000-5.

204. Wong E, Cuervo AM. Autophagy gone awry in neurodegenerative diseases. Nat Neurosci. 2010;13(7):805-11.

Ready to submit your research? Choose BMC and benefit from:

- fast, convenient online submission

- thorough peer review by experienced researchers in your field

- rapid publication on acceptance

- support for research data, including large and complex data types

- gold Open Access which fosters wider collaboration and increased citations

- maximum visibility for your research: over $100 \mathrm{M}$ website views per year

At $\mathrm{BMC}$, research is always in progress.

Learn more biomedcentral.com/submissions 